\title{
Continuing education interventions about person-centered care targeted for nurses in older people long-term care: a systematic review
}

\author{
Mari Pakkonen ${ }^{1 *}$ (D), Minna Stolt ${ }^{1}$ (D, Andreas Charalambous ${ }^{1,2}$ (i) and Riitta Suhonen ${ }^{1,3,4}$ (D)
}

\begin{abstract}
Background: Person-Centered Care is often seen as an indicator of quality of care. However, it is not known whether and to what extent person-centered care can be enhanced by continuing education interventions in older people's long-term care settings. This systematic review aimed to analyze and synthesize the existing research literature about person-centered care-based continuing educational interventions for nurses working in long-term care settings for older people.

Methods: Five databases were searched 6/2019 and updated 7/2020; PubMed (Medline), CINAHL, PsycINFO, Cochrane and Eric using the keywords person-centered car* OR person-centred car * OR patient-centered car* OR client-centered car* OR tailored car* OR resident-centered car* OR individualized car* AND older* OR elder* OR old person* AND Long-Term Care OR Nursing home OR 24-h treatment OR long-term treatment. Twenty-seven full texts from 2587 initially retrieved citations were included.

Results: The continuing educational interventions found were divided into five themes: person-centered interventions focusing on medication; interaction and caring culture; nurses' job satisfaction; nursing activities; and older people's quality of life. The perspective of older people and their next of kin about the influence of continuing education interventions were largely absent. The background theories about interventions, the measurements taken, and the clarity around the building blocks of the continuing-care interventions need further empirical verification. The pedagogical methods used were mainly quite behavioristic mostly lectures and seminars.

Conclusion: Most of person-centered care continuing education interventions are effective. Still more empirical research-based continuing education interventions are needed that include learner-centered pedagogical methods, with measurable outcomes that consider the opinions of older people and their next of kin. Continuing educational interventions for nurses need to be further developed to strengthen nurse's competence in person-centered care, job satisfaction and for better quality of care.
\end{abstract}

Keywords: Person-centered care, Continuing education, Older people, Long-term care, Intervention, Review

\footnotetext{
* Correspondence: mjpakk@utu.fi

'Department of Nursing Science, University of Turku, Turku, Finland

Full list of author information is available at the end of the article 


\section{Background}

The requirements for quality in the nursing care of older people has been written in most countries into: legislation [1], national guidelines [2, 3] and policy papers [4]. The requirements are also written into international ethical guidelines [5, 6] and e.g. in Finland's legislation [7, 8]. (Ministry of Social Affairs and Health, 2018; Finlex, $980 / 2012$ ). Person-centered care is often used as a quality indicator and is of ethical value [2-8].

The conceptual roots of person-centered care are in theories based on the philosophy of humanism, which includes personhood and well-being theory [9], personality theory [10] and nursing theories $[11,12]$. In the nursing literature, the concept of person-centered care is often used as a synonym for other terms, such as individualized care, patient-centered care, client-centered care, and personalized care [13]. However, these concepts have differences. The concept of individualized care considers an individual as a biopsychosocial integral whole, focuses on individual differences, preferences, and the values of individuals. Individualized care includes the patient's clinical situation, personal life situation and decisional control [11]. Person- and patientcentered care concepts have different goals. Patientcentered care considers the patient as the center and prioritizes functional life, whilst the person-centered care takes a wider stance prioritizing the whole life, including the interactions with others and the achievement of a meaningful life [14]. The way in which people are cared for often defines which concept is used in practice, for example, if person is given the status of a client or patient [13]. The core of each of the care concepts is human autonomy and respect for dignity [11, 13-15]. Person-centered care asserts its strong place in the care of older people because it is associated with the quality of life [16] and experiences of the quality of care [17] with a whole life orientation including, but not limited to a health problem orientation [14].

Continuing Education been defined in terms of continuing professional development, in-service training, or further training [18]. Usually the purpose of continuing education, which takes place after formal nurse registration education, is to develop nurses' competence [19]. In different hospital settings, individual nurse's competence consists of personal skills, abilities, and knowledge [20]. The collective competence of a group or team of nurses has a broader base and is greater than that of the sum of the individuals' competence, facilitating the growth and development of individuals with varying competence within the team [21]. Organizational culture has been found to affect the quality of care delivery by nursing teams, both positively and negatively [22]. Therefore, the promotion of competence through in long-term care is important, not only for individual nurses but also the collective competence of the team.

Young people's perceptions of the nursing profession are quite negative [23]. Nurses (Registered Nurses, Practical Nurses and Nursing Assistants) have reported a high level of job strain in nursing homes where the many residents suffer from dementia [24]. Nurses have and suggested there is poor support from the organization managers for the quality of their work in long-term care [25]. The use of person-centered care may mitigate these issues by reducing stress, burnout, and improving job satisfaction among dementia care nurses, though the research in this area is currently weak making firm conclusions difficult [26]. Person-centered care interventions that have a positive influence in older people's long-term care discussed in the literature include: environmental changes; interaction relationships; relationships with managers; the empowerment of nurses; staff-resident relationships and the care culture so that care is more about the individual [27]. Psychosocial interventions in person-centered care of older people in long-term care include elements such as: communication training; emotional response support; dementia care mapping; retaining abilities; sensory strategies; integrity-promoting care; organizational level changes; and others not categorized by researchers [28]. The outcomes of these interventions seem to support the use of person-centered care approach although generalizability of the results is limited due to the complexity of the interventions [27, 28]. However, there seems to be little useful evidence about the effects of person-centered continuing education interventions on nurses working with older people in long-term care and even less from the perspective older people and their next of kin. Given the importance of the topic, more needs to be known about the efficacy of person-centered care continuing education interventions, especially as the older people population increases [29] and older people are expected to live longer, many with long-term health conditions [30].

The aim of this review was to analyze and synthesize the existing research literature about person-centered care-based continuing educational interventions for nurses working in long-term care settings for older people. The goal was to increase the understanding of the current pedagogical methods and results of continuing education interventions from the perspective of nurses, older people and their next of kin.

\section{Methods}

This study is a systematic review of the empirical research literature after Harris [31] focused on personcentered care-based continuing education interventions for nurses working in long-term care settings for older 
people. The review was conducted following internationally recommended scientific practice in every phase [32] and reported according to Preferring Reporting Items for Systematic Reviews and Meta-Analyses PRISMA [33].

\section{Search strategy}

A systematic search from five relevant databases was conducted on 06/2019 and updated on 7/2020, published articles written in English without any time limit: PubMed (Medline), CINAHL, PsycINFO, Cochrane and ERIC using keywords and Boolean operators. The search phrase PubMed (Medline) was: ("Patient-Centered Care"[Mesh] OR person-centered car* OR person-centred car" OR "person centered care" OR "person centred care" OR "patient centered care" OR "patient centred care" OR patient-centered car* OR "patient-centred care" OR "client centered care" OR "client centred care" OR tailored car* OR "resident centered care" OR "resident centred care" OR "resident-centred care" OR "resident-centered care" OR individualized car" OR individualized car") AND ("Frail Elderly"[Mesh] OR "Aged"[Mesh] OR "Aged, 80 and over"[Mesh] OR "Senior Centers" [Mesh] OR older* OR elder* OR aged OR senior* OR resident* OR old people* OR old person*) AND ("Insurance, Long-Term Care"[Mesh] OR "LongTerm Care"[Mesh] OR "Nursing Homes"[Mesh] OR "After-Hours Care"[Mesh] OR "Conservative Treatment"[Mesh] OR long-term car" OR LTC OR nursing home* OR 24-h treatment" OR 24-h car* OR enhanced treatment* OR enhanced car* OR long-term treatment*).

\section{Study selection}

Studies were included in the review if they were: (1) experimental study designs; RCTs; controlled clinical trials (CCTs); quasi-experimental and pre-posttest studies with or without control groups. (2) intervention studies with person-centered care elements; (3) studies focused on continuing education interventions for nurses working in long-term settings for older people; and (4) peerreviewed research studies published in the English language. Studies were excluded if they were (1) implementation studies or feasibility studies not assessing any outcomes and (2) interventions other than personcentered care-based continuing educational interventions for nurses working in long-term care settings for older people.

Retrieval of the studies was conducted in four steps [33] (Fig. 1). The initial search of the databases retrieved 2587 citations. After removing duplicate studies $(n=$ 277), in the second step, three researchers (MP, MS and RS) screened the titles and abstracts to identify eligible records for full text analysis removing 2310 scripts. In the third step the remaining 47 papers were analyzed against the inclusion and exclusion criteria. During this analysis researchers eliminated 20 papers by consensus leaving 27 papers for further analysis. A manual search of the reference lists of the 27 included studies identified no further relevant studies.

\section{Quality appraisal}

The quality of the 27 included papers was assessed by Joanna Briggs Institute [34] checklist for quasiexperimental studies. The aim of the appraisals was to assess methodological quality of studies considering bias in designs, research conduct and the analyses with nine appraisal questions and a maximum score of 9. The quality appraisal was recorded but not used as part of the inclusion criteria.

\section{Data analysis}

Data were collected in tabular format: the author(s); year of publication; country of origin; design; aim of study; sample; participants; data collection instruments; and methods. The contents, pedagogical methods and outcomes from the perspective of Nurses $(\mathrm{N})$, Next of kin (NK) and Older People (OP) were also collected within the same tabular format. The outcomes of the interventions, positive or no effect, were analyzed using a twostep categorization $(+=\mathrm{a}$ positive effect of the intervention, $0=$ no effect of the intervention). As the outcome variables differed from each other it was not possible to calculate meta-analysis. Data were analyzed using conventional content analysis [35]. The original expressions used by authors in their articles were used to reduce interpretation. The analysis was performed by one researcher and the results were confirmed in the research team before tabulation.

\section{Results}

\section{Characteristics of the studies}

The studies (Table 1) were carried out mainly in Europe: Portugal $(n=5)$; Sweden $(n=1)$; UK $(n=2)$ Belgium $(n=3)$ Germany $(n=1)$ The Netherlands $(n=2)$ and also, in USA $(n=7)$; Australia $(n=4)$; Canada $(n=1)$ and Japan $(n=1)$. The studies were published between 2004 and 2019, mostly in 2015 or after $(n=19)$.

The design of the studies were RCTs $(n=9)$, experimental designs $(n=6)$, quasi-experimental design $(n=$ $2)$, pretest-posttest designs $(n=10)$. All studies conducted pretests and posttests after the intervention. Four studies were carried out without control group and there were two experimental groups in one RCT design. The quality appraisal, mean and median scores using the JBI checklist, were 7.70 and 9 , out of nine respectively.

The study informants were mainly older people $(n=$ $11)$, nurses $(n=7)$ or both together $(n=6)$. In one study nurses responded as a team. In another study nurses and 


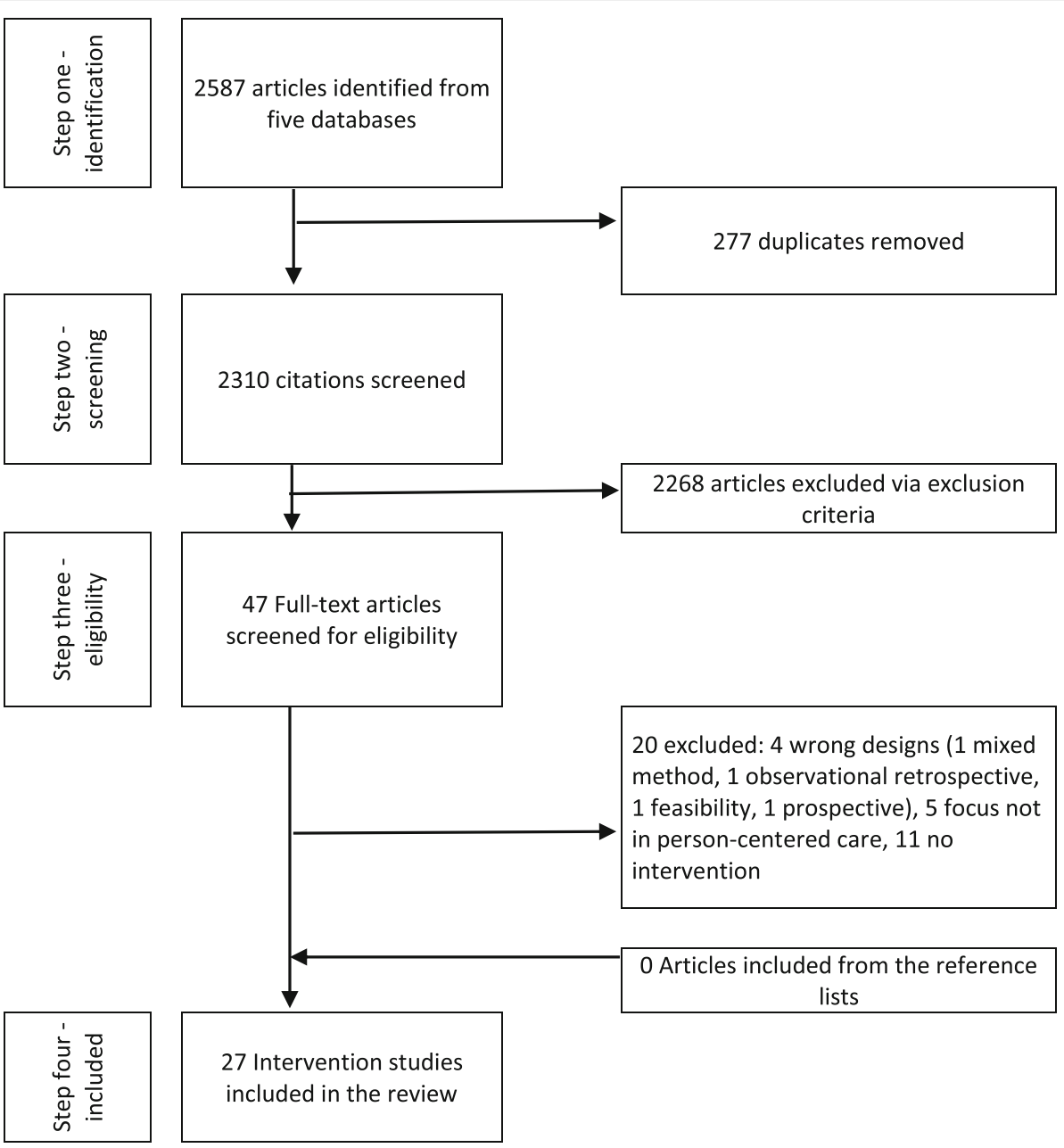

Fig. 1 Retrieval of the studies

older people formed a dyad. The next of kin of the older people participated in one study together with older people and nurses. In the experimental groups, the mean and mode of the participants were 82 (range 6-677) and 24 respectively. In the control groups the mean and mode were 100 (range 6-660) and 29 respectively.

\section{Implementation of the continuing education interventions}

The pedagogical methods used in the continuing education interventions (Table 2) were contact teaching via seminars, workshops, or team sessions $(n=27)$, usually with the on-site support $(n=17)$. In some studies, a few "key nurses", attended continuing education $(n=5)$. Within the continuing education sessions digital material such as videos were used $(n=8)$ and in one study simulation and role-playing games.

The continuing education interventions were categorized into five themes: (1) medication $(n=5)$; (2) interaction and caring culture $(n=11)$; (3) nurses' job satisfaction ( $n=3)$; (4) nursing activities $(n=5)$; and (5) older people's quality of life $(n=3)$. In the medication themed interventions, the typical goal was to reduce the number of medications older people took and to learn to use person-centered care to reduce behavioral issues that disturbed other residents. The aim of the interaction and care culture themed interventions was to increase positive communication between nurses and the older people and to influence the caring culture, making it more person-centered. Some continuing education interventions focused on increasing nurses' job satisfaction. Nursing activities themed interventions were aimed at influencing residents' daily routines and activities.

\section{Outcomes of the continuing education interventions}

Most of the continuing education interventions about person-centered care had positive effects (Table 2) but four studies indicated that the interventions did not have the any effect $[50,53,61,68]$. 
Table 1 Studies included in the review $(n=27)$

\begin{tabular}{lll}
\hline $\begin{array}{l}\text { Authors, Design and JBI Aim } \\
\text { year, } \\
\text { country }\end{array}$ & $\begin{array}{l}\text { Number of Instrument(s) } \\
\text { participants in } \\
\text { last } \\
\text { measurement } \\
\text { point }\end{array}$ \\
\hline
\end{tabular}

\begin{tabular}{lll}
\hline Azermai & Pre-post and follow-up & To evaluate the reduce the psychotropic \\
et al. [36], & intervention with control & $\begin{array}{l}\text { drug use and to improve prescribing } \\
\text { 2017, }\end{array}$ \\
group & practice via intervention
\end{tabular}

Belgium $\quad \mathrm{JB}=7$

Ballard et al. Randomised controlled

[38], 2018, cluster trial

United $\quad \mathrm{JB}=9$

Kingdom
Barbosa

et al. [42],

2017,

Portugal

Barbosa

et al. [44],

2016a,

Portugal

Barbosa

et al. [46],

2016b,

Portugal
Experimental, pre-posttest control group design $\mathrm{JB} \mid=9$

Experimental, pre-posttest control group design $\mathrm{JB} \mid=9$

Experimental, pre-posttest control group design $\mathrm{JB} \mid=9$

Barbosa et al. [47], 2015,

Portugal

Experimental, pre-posttest control group design $\mathrm{JB} \mid=9$

Boersma et al. [48], 2019, Quasi-experimental, prepost-test control group design

Netherlands $\quad \mathrm{J} \mathrm{B} I=9$
To evaluate the efficacy of a personcentered care and antipsychotic review on Quality of Life, agitation and antipychotic use in people with dementia living in nursing homes, and to determine its cost.

To assess the effects of a Psychoeducational programme on the quality of direct care workers interactions with residents with dementia.

To assess the effects of a person-centered care based psychoeducational intervention on direct care workers verbal and nonverba communicative behaviors with residents with dementia during morning care.

To assess the 6-month effects of a personcentered care-based Psychoeducational intervention targeted at direct care workers caring for people with dementia in agedcare facilities

To assess the effects of a person-centered care-based psychoeducational intervention to direct care workers stress, burnout, and job satisfaction.

To assess the implementation of the Veder contact method (VCM) in 24-h care.

to assess how working with the Veder

Boersma

Non-randomized

et al. [49], controlled tria

2017 $\mathrm{JB} \mid=8$

Netherlands

Bökberg et al .[50],

2019,

Experimental, pre-posttest control group design $\mathrm{JB} \mid=9$

Sweden

\section{Residents in nursing homes. \\ E: $n=118$ \\ C: $n=275$ \\ A: $n=393$ \\ Older people in nursing homes. \\ $\mathrm{E}: n=257$ \\ $C: n=296$ \\ A: $n=553$} with dementia

Direct care workers in aged-care

facilities.

$\mathrm{E}: n=27 \mathrm{C}: n=$

$29 \mathrm{~A}: n=56$

Direct care workers in aged-care facilities. $\mathrm{E}: n=27 \mathrm{C}: n=$ $29 \mathrm{~A}: n=56$

Direct care workers in aged-care facilities. $\mathrm{E}: n=24 \mathrm{C}: n=$ 29 A: $n=53$

Direct care workers in aged-care facilities.

$\mathrm{E}: n=27$

C: $n=29$

A: $n=56$

Professional

Caregivers

E: $n=79$

$\mathrm{C}: n=57$

A: $n=136$

Residents

$\mathrm{E}: n=78$

$\mathrm{C}: n=61$

A: $n=139$

Caregivers from nursing homes.

$\mathrm{E}: n=75$

C: $n=36$

A: $n=111$

Staff members in nursing homes.

E: $n=167$

$C: n=198$

A: $n=365$

Residents in
* Psychotropic Education and Knowledge test [37]

* Medication charts

* Health-related quality of life of people with dementia 31 items [39]

* Medication charts

* Agitation Inventory 29 items [40]

* The Neuropsychiatric Inventory 12 domains [41]

* Video-recorded sessions coded by Global Behavioral Scale [43]

* Ethogram for verbal communicative behaviors by framework of Kitwood [45]

* Perceived Stress Scale 13 items

* Maslach Burnout Inventory 22 items in 3 subscales

* Minnesota Satisfaction Questionnaire 20

items in 2 subscales

* Ethogram for verbal communicative behaviors by framework of Kitwood [45]

* Perceived Stress Scale 13 items

* Maslach Burnout Inventory 22 items in 3 subscales

* Minnesota Satisfaction Questionnaire 20

items in 2 subscales

* 8 focus group interviews

* Quality of Caregivers' Behavior in dementia care (QCB) 25 items

* Approaches to Dementia Questionnaire (ADQ) 19 statements

* Quality of implementation of VCM score

* QUALIDEM observation tool

* INTERACT observation tool

* Observation $3 \mathrm{~h}+3 \mathrm{~h}$

* Job satisfaction (Leiden Quality of Work Questionnaire) 23 items * Focus group interviews

* Interviews of managers

* Person-centered Care Assessment Tool 13 items in 2 subscales [51]

* Person-Centered Climate Questionnaire 14 items in 3 subscales [52]

(Continued)

* Person-Centered Environment and Care 
Table 1 Studies included in the review $(n=27)$ (Continued)

\begin{tabular}{lll}
\hline $\begin{array}{l}\text { Authors, Design and JBI } \\
\text { year, } \\
\text { country }\end{array}$ & Aim & Number of \\
& & participants in \\
last & measurement \\
& & point
\end{tabular}

et al. [53], $\quad \mathrm{JBl}=9$

2014,

Australia

Chenoweth Cluster-randomized trial et al. [56], JBI $=9$

2009,

Australia

Coleman \& Medvene [57], 2013, USA
Person-centered care (PCC), person-centered environment (PCE) and PCC + PCE interventions to quality of life and agitation for people with dementia in nursing houses.
To compare effectiveness of Personcentered care (PCC), Dementia Care Mapping (DCM) and usual care and these methods decreases to dementiacompromised behaviors, quality of life, use of psychotropic drugs and injuries. The estimated cost differences between the treatments were also of interest
Quasi-experimental, waitlist control design $\mathrm{JB} \mid=9$
Cornelison et al. [61], 2019, USA
A multi-arm, pre-post intervention study $\mathrm{JB} \mid=6$
Fossey et al. Cluster randomised

[62], 2006, controlled tria

United $\quad J B I=8$

Kingdom

Gillis et al. Pre-posttest design, [63], 2019, without control group Belgium

Hoeffer et al. [64], 2006, USA $\mathrm{JB} \mid=6$

Randomized controlled trial with crossover design $\mathrm{JB} \mid=9$
To pilot test a multicomponent intervention to increase certified nursin assistans' awareness of Person-centered care and to establish the feasibility of implementing an intervention involving videotaped biographies of residents and videotapes of resident/ nursin assistans' caregiving interactions.

To evaluate how nursing homes, perceive their adoption of person-centered care prac tices across seven domains and how these perceptions change in response to an educ tional intervention embedded in a statewide program, Promoting Excellent Alternatives in Kansas nursing homes

To assess effectiveness of a training and support intervention for nursing home staff in reducing the proportion of residents with dementia who are prescribed neuroleptics.

To test a person-centred team approach for addressing agitated or aggressive behaviour amongst nursing home residents with dementia.

To test the efficacy of two person-centered care-based bathing interventions to improve caregiving behavior during bathing.
Residents / CNAs dyads.

$\mathrm{E}: n=11$ dyads C: $n=8$ dyads A: $n=19$ dyads Staff teams from nursing homes: E: $n=($ Preadopters) 82 C: $n=$ (Adopters) 86

A: $n=168$

Residents in nursing homes

E: $n=176$

C: $n=170$

Residents in nursing home $n=65$

Residents

$\mathrm{E} 1: n=24 ; \mathrm{E} 2$ : $n=22$

C: $n=23$

A: $n=69$

Nursing assistants

E: $n=24$

C: $n=13$

A: $n=37$

Staff members

\section{Instrument(s)}

Assessment Tool [54]

* Cohen-mansfield Agitation Inventory [40]

* Person with Dementia and Quality of

life measurement [55]

* Emotional Responses in Care

* Global Deterioration Scale of Primary

Degenarative Dementia

* Residents activities of daily living

* Cornell Scale for Depression in

Dementia

* Quality of Interactions Schedule

* Cohen-Mansfield Agitation Inventory

[40]

* Neuropsychiatric Inventory for the nursing home

* Quality of Life measurement

* Observation

* Recorded information about the drugs

* The Therepeutic Environment Screening

Survey for Nursing Homes

* Interviews

* Report of economic analysis

* Video recorded material code by Person-Centered Behavior Inventory and

Global Behavior Scale [58]

* Relationship between residents and CNAs measured by Resident Satisfaction Index 27- items and Subscale of the Maslach Burnout Inventory "Personal Accomplishment" 8-items [59] and Mutuality Scale 15-items [60]

* Kansas Culture Change Instrument 68 -items in 7 dimensions

* Cohen-Mansfield Agitation Inventory [40]

* Dementia Care Mapping (DCM)

* Medication charts

* Neuropsychiatric Inventory - Nursing Home Version (NPI-NH) 12 symptoms

* Cohen-Mansfield Agitation Inventory (CMAl) 29 items

* Video-recoded sessions coded by The Caregiver Bathing Behavior Rating Scale * Care Effectiveness Scale two scales; The Confidence Scale 6 items, The Easy Scale 3 items

* The Hassless During Bathing Scale eight items 
Table 1 Studies included in the review $(n=27)$ (Continued)

\begin{tabular}{lll}
\hline $\begin{array}{l}\text { Authors, Design and JBI Aim } \\
\text { year, } \\
\text { country }\end{array}$ & & $\begin{array}{l}\text { Number of Instrument(s) } \\
\text { participants in } \\
\text { last } \\
\text { measurement } \\
\text { point }\end{array}$ \\
\hline
\end{tabular}

\begin{tabular}{ll}
\hline [65], & $J B I=9$ \\
2012, & \\
Australia & \\
& \\
Li et al. [66], & Pre-post controlled trial \\
2017, USA & JBI $=7$
\end{tabular}

centered care (PCC), Dementia Care Map-
ping (DCM) and usual care on staff burnout,
well-being, attitudes and reactions toward
behavioral disturbances of residents with
dementia.
To test the effects of a Person-Centered De-
mentia Care intervention on sleep in
residents.

to examine the effectiveness of individualized communication plans tailored to the needs of residents with dementia.
McGilton

et al. [67],

2017,

Canada
Pre-posttest design, without control group $\mathrm{JBI}=7$
Richter et al. Cluster-randomised [68], 2019, controlled trial Germany $\quad J B I=9$ to adopt the person-centred care intervention from UK to German conditions and test its effectiveness

\section{in nursing \\ homes: \\ E: \\ PCC $n=56$ \\ DCM $n=45$ \\ C: $n=23$ \\ A: $n=123$}

Residents in dementia care units. E: $n=16$ C: $n=6$

A: $n=22$

Residents in nursing home $n=12$ and nurses $n=$ 20 A: $n=32$
Services Survey [59]

* General Health Questionnaire

$\begin{aligned} & \text { E: } n=493 \\ & \text { C: } n=660 \\ \text { A: } n=1153 & \end{aligned}$

Roberts

et al. [69],

2015,

Australia
Pre-posttest mixed method design, without control group $\mathrm{J} B \mathrm{I}=6$

Sloane et al. Pre-posttest design, [70], 2013, without control group USA $\quad J B I=5$

to describe the development of a composite model of care based personcentered care and report evaluation and results of a pilot project exploring the new model's feasibility

to develop and test a person-centered evidence-based mouth care program in nursing homes
Sloane et al. Randomized Controlled [71], 2004, trial, with two

USA experimental groups and crossover $\mathrm{JB} \mid=9$ to evaluate the efficacy two nonpharmacological based person-centered care techniques in reducing agtation, aggression and discomfort in shower and towel bath situations in nursing home residents with dementia
* Actiwatch Spectrum (small device)

* Dementia Care Mapping (DCM)

* Brief Interview for mental Status

* Cumulative Illness Rating Score for Geriatrics

* Mini-Mental State Examination / Color Vision test / Audiometer Test / acuity test

* Functional Linguistic Communication Inventory

*Cornell Scale for Depression in Dementia 19 items

* The Alzheimer Disease-related Quality of Life 40 items

* Katz index of ADL 6 items

* Communication-Imparment Questionnaire 8 items

* Interactional Comfort Survey 5 domains

* The Satisfaction Working with Residents with Dementia 21 items

* Nursing Care Assessment Scale 28 items

* Interviews (focus group and individual)

* Observation

* Documents of residents

* Quality of Life in Alzheimer's Disease Scale

* Dementia Screening Scale

* Cohen-Mansfield Agitation Inventory

[40]

* Prescriptions of antipsychotics

* Safety parameters

Staff members * Medication charts

$n=15 \quad *$ Cohen Mansfield Agitation Inventory

Residents $n=\quad$ [40]

16 * Dementia Care Mapping (DCM)

Next of kin $n=\quad *$ Interviews by using (Resident/Relative 15 Audit Tools and Tool for Understanding A: $n=46 \quad$ Residents Needs as Individual Persons')

Residents in * Plaque Index for Long-Term Care nursing homes * Gingival Index for Long-Term Care $n=88 \quad *$ Denture Plaque Index

Nursing * Minimum Data Set

assistants $n=6 \quad$ * Videotaping; Noldus Information A: $n=94 \quad$ Technology Wageningen / Mouth Care

Task Completion Form

* Nursing home records about resident's individual health situations

Residents in * Videotaping

nursing homes * Care Recipient Behavior Assessment E: $\quad$ * Discomfort Scale for Dementia of an

$n=24 /$ group A Alzheimer Type 6 items

$n=25 /$ group B * Hardy Skin Condition Data Form

C: $n=24 \quad$ * Skin cultures

Nursing $\quad *$ Activities of Daily Living

assistants $\quad *$ Cumulative Index Rating Scale for 
Table 1 Studies included in the review $(n=27)$ (Continued)

\begin{tabular}{|c|c|c|c|c|}
\hline $\begin{array}{l}\text { Authors, } \\
\text { year, } \\
\text { country }\end{array}$ & Design and JBI & Aim & $\begin{array}{l}\text { Number of } \\
\text { participants in } \\
\text { last } \\
\text { measurement } \\
\text { point }\end{array}$ & Instrument(s) \\
\hline & & & $\begin{array}{l}\text { E: } n=24 \text { in } \\
\text { groups together } \\
\text { C: } n=13 \\
\text { A: } n=110\end{array}$ & $\begin{array}{l}\text { Geriatrics } \\
\text { * Cohen-Mansfield Agitation Inventory } \\
\text { [40]) } \\
{ }^{*} \text { Mini-Mental State Examination } \\
{ }^{*} \text { Cognition Scale } \\
{ }^{*} \text { Recorded Medication data }\end{array}$ \\
\hline $\begin{array}{l}\text { Sposito } \\
\text { et al. [72], } \\
2017, \\
\text { Portugal }\end{array}$ & $\begin{array}{l}\text { Quasi-experimental study, } \\
\text { with pre-posttest, without } \\
\text { control group } \\
\mathrm{JBI}=6\end{array}$ & $\begin{array}{l}\text { To assess effectiveness of person-centered } \\
\text { care, Multisensory Simulation and Motor } \\
\text { Simulation intervention in residents' behav- } \\
\text { ior during the morning care. }\end{array}$ & $\begin{array}{l}\text { Residents in } \\
\text { nursing homes: } \\
n=45 \\
\text { Direct care } \\
\text { Workers in } \\
\text { Nursing Homes: } \\
n=56 \\
\text { A: } n=101\end{array}$ & $\begin{array}{l}\text { * Mini-Mental State Examination } \\
\text { * The Global Deterioration Scale } \\
\text { * Video recordings }\end{array}$ \\
\hline $\begin{array}{l}\text { Wauters } \\
\text { et al. [73] } \\
\text { 2019, } \\
\text { Belgium }\end{array}$ & $\begin{array}{l}\text { Cohort study with cross- } \\
\text { sectional observations, } \\
\text { with pre-posttest, without } \\
\text { control group } \\
\mathrm{JBI}=5\end{array}$ & $\begin{array}{l}\text { To investigate whether the intervention, } \\
\text { starting from general intervention template, } \\
\text { could be successfully implemented in } \\
\text { separate nursing homes, resulting in a } \\
\text { decreased prevalence of psychotropic drug } \\
\text { users. }\end{array}$ & $\begin{array}{l}\text { Residents in five } \\
\text { different } \\
\text { nursing homes: } \\
n=677\end{array}$ & $\begin{array}{l}\text { * Medical records and electronic } \\
\text { medication charts } \\
{ }^{*} \text { Mini-Mental State Examination } \\
{ }^{*} \text { Katz Activities of Daily Living (mandatory } \\
\text { in Belgium) }\end{array}$ \\
\hline $\begin{array}{l}\text { Williams } \\
\text { et al. [74], } \\
\text { 2018, USA }\end{array}$ & $\begin{array}{l}\text { Pre-posttest design } \\
\text { without control group } \\
\mathrm{JBI}=6\end{array}$ & $\begin{array}{l}\text { to test four interdisciplinary strategies to } \\
\text { measure changes in person-centered com- } \\
\text { munication used by nursing home staff fol- } \\
\text { lowing intervention }\end{array}$ & $\begin{array}{l}\text { Nursing staff } \\
n=32 \\
\text { Residents } n= \\
49 \\
\text { A: } n=81\end{array}$ & $\begin{array}{l}\text { * Behavioral, psycholonguistic, emotional } \\
\text { tone coding of elderspeak } \\
\text { communication and content analysis of } \\
\text { communication topics }\end{array}$ \\
\hline $\begin{array}{l}\text { Yasuda \& } \\
\text { Sakakibara } \\
\text { [75], } \\
\text { 2017, Japan }\end{array}$ & $\begin{array}{l}\text { Pre-posttest design } \\
\text { without control group } \\
\mathrm{JB}=5\end{array}$ & $\begin{array}{l}\text { To assess the effects of care staff training } \\
\text { based on person-centered care and demen- } \\
\text { tia care mapping on the quality of life) of } \\
\text { residents with dementia in a nursing home }\end{array}$ & $\begin{array}{l}\text { Residents } n= \\
40\end{array}$ & $\begin{array}{l}\text { * Mini-Mental State Examination } \\
\text { * DCM (Dementia Care Mapping) } \\
\text { * Barthel Index }\end{array}$ \\
\hline
\end{tabular}

$J B I$ The Joanna Briggs Institute checklist for Quasi-Experimental Studies, E Experimental group, C Control groups, A All Participants, PCC Person-Centered Care, PCE Person-Centered Environment, DCM Dementia Care Mapping

Medication themed intervention outcomes described a significant decrease in use of psychotropic drugs [36, 73]. The proportion of residents using neuroleptic drugs in research centers was significantly lower than in control homes [62] which reduced costs [38]. Continuing education intervention influence on the staff and older people's behavior varied. The interventions had no effect on residents' behavioral symptoms such as agitation and disruption in one study, but these symptoms also did not increase with fewer medications [62]. In another study, continuing education intervention did reduce residents' agitation, their general neuropsychiatric symptoms and increased their positive interactions between nurses and residents [38].

Interaction and caring culture themed continuing education interventions had a positive influence on: nurses' person-centeredness [42]; verbal communication [44, 48, 71]; non-verbal communication [44]; increased direct gaze duration between residents and nurses; reduced sadness and increased smiling [72]. In one study, both nurses and residents reported increased satisfaction in their relationship after the continuing education intervention and residents reported a closer relationship with nurses [57]. Nurses reported increased knowledge about meeting the needs of people with dementia and organizational culture change experiences and next of kin were also satisfied with these changes and quality of care [69]. Also, positive effects on care providers' mood, burden [67] and residents' behaviour were reported [63].

Nurses' job satisfaction themed continuing education interventions seemed to positively influence nurse's emotional exhaustion, emotional management, self-care awareness and enhanced cohesion within the group, which can reduce nurses burnout [47]. One study had no significant effect on job satisfaction based on quantitative data analysis but included details of a qualitative analysis which showed a positive impact of the intervention on daily work performance [49]. It was suggested that without managerial support, the influence of the continuing education intervention would not be as strong and would be less likely to be established in the workplace [65].

Nursing activities themed continuing education interventions demonstrated the abstract nature of person- 
Table 2 Continuing education interventions, pedagogical methods, assessments, and their outcomes

\begin{tabular}{|c|c|c|c|}
\hline Theme & Content of intervention & Pedagogical methods & Assessments \\
\hline Medication & $\begin{array}{l}-" \text { Awareness-campaign" to } \\
\text { the nurses, next of kin and } \\
\text { residents } \\
\text { - Educational courses given } \\
\text { by experts (sleeping } \\
\text { problems, old age } \\
\text { depression, behavioral } \\
\text { problems) } \\
\text { - Professional support }\end{array}$ & $\begin{array}{l}\text { - Flyers, posters, and articles } \\
\text { in nursing home's own } \\
\text { newspaper } \\
\text { - } 3 \times 2 \mathrm{~h} \\
\text { - For } 10 \text { months two part- } \\
\text { time project staff-members } \\
\text { offered person-centred } \\
\text { professional support to the } \\
\text { nurses }\end{array}$ & $\begin{array}{l}\text { Drug use was recorded at } \\
\text { baseline, after } 10 \text { months } \\
\text { and after } 22 \text { months in } \\
\text { intervention home and only } \\
\text { medication data from } \\
\text { control nursing home. }\end{array}$ \\
\hline
\end{tabular}

\section{Outcomes and \\ effectiveness in lens of \\ nurses, older people and \\ next of kin}

P: Quality improvement initiative led to a significant decrease in the use of psychotropic drugs in the intervention group, even after 1-year follow-up. Education only had a limited effect, but education and professional support together had clearer effects in long-term.

$\mathrm{OP}=+$

- Orientation for managers, staff teams, WHELD champions and residents - WHELD champions (two/ each care home) training - on-site consultation

\section{- 2 days orientation - WHELD champions trained 4 months (1 day per month) \\ - On-site consultation $8 \mathrm{~h} /$ month/care home}

The quality of life of older people, reduced agitation, general neuropsychiatric symptoms, antipsychotic use, global deterioration, mood, unmet needs, mortality, quality of interactions, pain and cost were assessed at baseline and at 9 months after the intervention.

Daily dose of drugs, agitation, disruptive behaviour, and quality of life $\begin{array}{ll}\text { - Training and supporting by } & -10 \text { months training and } \\ \text { specialists such as a } & \text { supporting }\end{array}$ psychologist, occupational therapist or nurse including about the philosophy of person-centered care, positive care planning, awareness of environmental design issues, behavioral models, developing individual interventions, active listening, communication skills, reminiscence techniques and involvement of family careers.

- Supervision for the staff members, including systematic consultation home issues, didactic training, skills modelling

- Training and supporting by - Information about the
specialists such as a
study 60 min. psychologist, occupational - 2-day workshop therapist or nurse including - Supporting by experts about the philosophy of person-centered care, positive care planning, awareness of environmental design issues, behavioral models, developing individual interventions, active listening, communication skills, reminiscence techniques and involvement of family careers.

- Supervision for the staff members, including systematic consultation, home issues, didactic training, skills modelling
- Weekly supervision of groups and individual staff members
Antipsychotic drug use, prescriptions of antipsychotics and safety parameters as falls were assessed at baseline and after 3, 6, 9, and 12 months. Quality of life and agitation were assessed at baseline and after 12 months.
P: WHELD interventions improved the quality of life of older people

S: WHELD reduced agitation, and general neuropsychiatric symptoms, and increased the number of positive interactions between nurses and residents. There were also cost advantages.

$\mathrm{N}=+/ \mathrm{OP}=+$

$\mathrm{P}$ : The proportion of residents using neuroleptic drugs in research centers was significantly lower than in the control homes. $\mathrm{S}$ : There was no effective difference between intervention and control groups in behavioral symptoms, but behavioral symptoms did not increase when less drugs were used. $\mathrm{OP}=+$
Source

Azermai et al. [36],

Ballard et al. [38], 2018

Fossey et al. [62], 2006
$\mathrm{P}$ : The intervention did not reduce the use of antipsychotics in nursing homes in Germany, although a reduction was seen in the control group.

$\mathrm{S}$ : There were not statistically significant differences between the study groups in Quality of Life, agitation, falls, physical restrains or prescriptions of antipsychotics. $\mathrm{N}=0$
Richter et al. [68], 2019 
Table 2 Continuing education interventions, pedagogical methods, assessments, and their outcomes (Continued)

\begin{tabular}{|c|c|c|c|}
\hline Theme & Content of intervention & Pedagogical methods & Assessments \\
\hline & $\begin{array}{l}\text { - Education about sleeping } \\
\text { problems, depression in old } \\
\text { age, challenging behaviour. } \\
\text { Content of was focused on } \\
\text { evidence-based practice, re- } \\
\text { ductions in psychotropic } \\
\text { drug use and non- } \\
\text { pharmacological } \\
\text { alternatives. }\end{array}$ & $\begin{array}{l}\text { - Transition to person- } \\
\text { centred care by awareness } \\
\text { campaign } \\
\text { - Online and printed } \\
\text { material } \\
\text { - Educational sessions } \\
\text { (dose?), recorded and } \\
\text { available later online } \\
\text { - Assessment of } \\
\text { psychotropic drug use (GP/ } \\
\text { residents/ nurses /relatives) }\end{array}$ & $\begin{array}{l}\text { Psychotropic drugs use was } \\
\text { assessed at baseline and } \\
\text { after } 12 \text { months. }\end{array}$ \\
\hline
\end{tabular}

\section{Outcomes and \\ effectiveness in lens of \\ nurses, older people and \\ next of kin}

$\mathrm{P}$ : The intervention resulted in a significant decrease in psychotropic drug use among nursing home residents after 12 months.

The combination of education, professional support, and the transition towards patient-centred care proved successful in discontinuation of high in-house psychotropic drug like hypnosedative and antidepressant use, except antipsychotics.

$\mathrm{OP}=+$

Interaction - Education to enhance and caring nurses knowledge and skills culture eight themes: person- nurses centered care and dementia, the emotional impact of caregiving, communication in dementia, conflict management, challenging behaviours, teamwork, the environment and dementia motor simulation, problem solving, relaxation and multisensory stimulation.

- Individual assisted sessions

for nurses by experts

- Supportive to improve nurses ability to cope with job-related stress and burnout

- Education to enhance nurses knowledge and skills concerning personcentered dementia care in eight themes: Personcentered care and dementia, the emotional impact of caregiving, communication in dementia, conflict management, challenging behaviours, teamwork, the environment and dementia, motor simulation, problem solving, relaxation and multisensory stimulation

- Individual assisted sessions for nurses by experts

- Support to improve nurses' ability to cope with jobrelated stress and burnout.

- Education to enhance nurses knowledge and skills concerning personcentered dementia care in eight themes: Personcentered care and dementia, the emotional impact
- Eight weekly session, 90 min per time

- Three days after session, individual sessions with

Direct care workers personcentredness video-recorded and then coded by global behavioral scale were assessed at baseline and after 8 weeks in the end of the intervention.

- Eight weekly session, 90 min per time

- Three days after session, individual sessions with nurses

- Eight weekly session of 90

- Three days after session, individual sessions with nurses
Direct care workers communicative behaviours with people with dementia were video-recorded and assessed at baseline and 2 weeks after eight-week intervention.
OC: Person-centered carebased continuing education intervention can be effective during the morning care to residents with dementia. It may increase nurses personcenteredness. Stress support for the test group was not effective.

$\mathrm{N}=+$

Source

Wauters et al. [73], 2019

Barbosa et al. [42], 2017

OC: Experimental group had a broader impact with the frequency of all behaviour categories than the control group. Experimental group had more verbal and nonverbal communication than the control group.

$\mathrm{N}=+$
Barbosa et al. [44], $2016 \mathrm{a}$
Direct care workers' stress, burnout, job satisfaction, and person-centered communicative behavior with people with dementia were assessed baseline, after eight-week intervention and after 6
OC: Person-centered carebased continuing education is effective for reducing nurses' burnout and improving communicative behaviors, up to 6 months after the intervention. Thus, the
Barbosa et al. [46], $2016 b$ 
Table 2 Continuing education interventions, pedagogical methods, assessments, and their outcomes (Continued)

\begin{tabular}{|c|c|c|c|c|c|}
\hline Theme & Content of intervention & Pedagogical methods & Assessments & $\begin{array}{l}\text { Outcomes and } \\
\text { effectiveness in lens of } \\
\text { nurses, older people and } \\
\text { next of kin }\end{array}$ & Source \\
\hline & $\begin{array}{l}\text { of caregiving, communica- } \\
\text { tion in dementia, conflict } \\
\text { management, challenging } \\
\text { behaviours, teamwork, the } \\
\text { environment and dementia, } \\
\text { motor simulation, problem } \\
\text { solving, relaxation and mul- } \\
\text { tisensory stimulation } \\
\text { - Individual assisted sessions } \\
\text { for nurses by experts } \\
\text { - Supportive to improve } \\
\text { nurses' ability to cope with } \\
\text { job-related stress and } \\
\text { burnout }\end{array}$ & & months follow-up. & $\begin{array}{l}\text { impact on stress levels sees } \\
\text { to deteriorate after } 6 \text { months. } \\
\text { Continuing education inter- } \\
\text { vention did not influence } \\
\text { the job satisfaction. } \\
\mathrm{N}=+\end{array}$ & \\
\hline & $\begin{array}{l}\text { - Functioning of long-term } \\
\text { memory in people with de- } \\
\text { mentia, reminiscing and } \\
\text { one-to-one contact } \\
\text { - Theatrical communication; } \\
\text { importance of the" saying } \\
\text { goodbye" ritual and } \\
\text { relation with the life history } \\
\text { of residents } \\
\text { - Repeating the information } \\
\text { from the first three } \\
\text { monthly sessions and } \\
\text { discussing the experiences } \\
\text { of caregivers and the } \\
\text { reactions of residents when }\end{array}$ & $\begin{array}{l}\text { - Three monthly training } \\
\text { sessions of } 3 \mathrm{~h} \\
\text { - Three on-the-job coaching } \\
\text { training sessions ( } 1 \mathrm{~h} \text { per } \\
\text { session) before training } \\
\text { sessions. } \\
\text { - Two } 3 \mathrm{~h} \text { follow-up training } \\
\text { sessions }\end{array}$ & $\begin{array}{l}\text { Attitude of professional } \\
\text { caregivers and self-rated abil- } \\
\text { ity to work with a care plan } \\
\text { were assessed by measure- } \\
\text { ments at baseline and at the } \\
\text { end of the one-year } \\
\text { intervention. } \\
\text { The communicative } \\
\text { behaviour of caregivers and } \\
\text { residents' behaviour were } \\
\text { observed at baseline and at } \\
\text { the end of the intervention. }\end{array}$ & $\begin{array}{l}\text { OC: Significant } \\
\text { improvements in caregivers' } \\
\text { communicative behavior and } \\
\text { some aspects of residents' } \\
\text { behavior and quality of life } \\
\text { were found on the } \\
\text { experimental wards with a } \\
\text { high implementation score. } \\
\text { No significant differences } \\
\text { were found between the } \\
\text { groups in caregivers' } \\
\text { attitudes, residents' care } \\
\text { plans, or mood. } \\
\mathrm{N}=+/ 0 \\
\mathrm{OP}=+/ 0\end{array}$ & $\begin{array}{l}\text { Boersma } \\
\text { et al. [48], } \\
2019\end{array}$ \\
\hline
\end{tabular}
applying VCM

- Connection is made with the" authentic self" of the caregivers and exercise in how to start up a communication according VCM and related to the life history of residents as described in their care plan

- Education including lectures on personcentered care, communication and relationships.

- 4 X $1 \mathrm{~h}$ sessions
- Demonstration videos,
homeworks, discussion,
using an interaction
worksheet.
worksheet.

\section{Content of intervention \\ - Education by mentor homes \\ - Workbook \\ - DVDs}

\section{Pedagogical methods}

Nursing assistants' awareness of Person-centered care and interactions with residents and nursing assistants were assessed at baseline, 6 weeks after intervention and 7 weeks after that.
OC: Theory-driven personcentered training intervention for nurses could be developed and implemented in Nursing Homes. Residents reported a closeness of relationship with the CNA. Both CNAs and residents reported increased satisfaction in their relationship after the training period.

$\mathrm{N}=+$

$\mathrm{OP}=+$

Results and effectiveness in lens of nurses, older people and next of kin

OC: Pre-adopters had lower scores 1 year after the education. This may be influenced the conceptualizing of person-centered care during the education. Better understanding of the concept of person-centered care can improve the rate of
Coleman \& Medvene [57], 2013

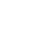

Boersma

tal. [48], their adoption of personassessed at baseline and after one-year education.
Source

Cornelison et al. [61], 2019 
Table 2 Continuing education interventions, pedagogical methods, assessments, and their outcomes (Continued)

\begin{tabular}{llll}
\hline Theme $\quad$ Content of intervention & Pedagogical methods & Assessments & $\begin{array}{l}\text { Outcomes and } \\
\text { effectiveness in lens of } \\
\text { nurses, older people and } \\
\text { next of kin }\end{array}$
\end{tabular}

adoption. Education and training are important when changing the caring culture. The nurses role in the perception of person-centered care practices is important. $\mathrm{N}=0$

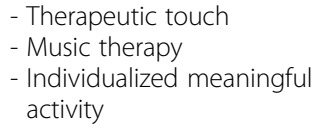

- Information about the project and the engagement of doctors, nurses, managers and the older people's next of kin to the project

- Education about the dementia care and Montessori activity training

- Support system

- Environment changes
Non-pharmacological intervention based on the resident's underlying needs was assessed at baseline and 3 days after the last session in 2 months intervention time.

\section{- 4-h workshop - Support by experts}

- Four days education - One day / month consultation on nursing home

- Support by phone and email

Residents mood and daily functioning were assessed at baseline and 10 weeks after the care providers were instructed in using the communication plans. Care providers' attitudes, satisfaction, and burden were assessed at baseline and 10 weeks following the workshop.

ABLE model was assessed at baseline and 12-14 months after the intervention.

Changing Talk communication intervention was assessed by collected video recordings at baseline, immediately after the 3 weeks intervention and at three-month follow-up.
OC: The frequency of aggression, loss of decorum depression and the severity of aggression decreased for all three interventions. Person-centred team-based approach is effective to reduce agitated or aggressive behaviour amongst nursing home residents.

$\mathrm{OP}=+$

OC: Individually tailored resident interventions may improve the quality of life of residents with dementia. Also positive effects on care providers' mood and burden were measured.

$\mathrm{N}=+$

$\mathrm{OP}=+$

OC: Significant behavior changes were evident among residents. Staff reported increased knowledge about meeting the needs of people with dementia and organizational culture change experiences. Next of kin were satisfied for the changes.

$\mathrm{N}=+$

$\mathrm{NK}=+$

$\mathrm{OP}=+$

OC: Post-intervention improvements in communication occurred for each measure; however, the changes were statistically significant only for behavioral and psycholinguistic measures. Methods and results for each communication measure were compared. $\mathrm{N}=+$

$\mathrm{OP}=+$
Gillis et al. [63] 2019

McGilton et al. [67], 2017

Roberts et al. [69], 2015 
Table 2 Continuing education interventions, pedagogical methods, assessments, and their outcomes (Continued)

\begin{tabular}{|c|c|c|c|c|}
\hline Theme & Content of intervention & Pedagogical methods & Assessments & $\begin{array}{l}\text { Outcomes and } \\
\text { effectiveness in lens of } \\
\text { nurses, older people and } \\
\text { next of kin }\end{array}$ \\
\hline & $\begin{array}{l}\text { - Knowledge and skill } \\
\text { concerning of person- } \\
\text { centered care. } \\
\text { - Information on dementia, } \\
\text { verbal and non-verbal com- } \\
\text { munication strategies, mul- } \\
\text { tisensory stimulation types. }\end{array}$ & $\begin{array}{l}\text { - } 8 \text { weekly group sessions } \\
\text { ( } 90 \text { min/session) by experts } \\
\text { - Group discussions, } \\
\text { simulations, homework } \\
\text { exercises, role-playings and } \\
\text { brainstorming }\end{array}$ & $\begin{array}{l}\text { Multisensory and motor } \\
\text { stimulation intervention } \\
\text { effects were assessed at } \\
\text { baseline and after the eight- } \\
\text { weeks intervention through } \\
\text { video-recordings. }\end{array}$ & $\begin{array}{l}\text { P: Intervention seems to } \\
\text { increase the frequency of } \\
\text { engagement in the morning } \\
\text { tasks. } \\
\text { S: Residents' frequency of } \\
\text { closing their eyes decreased. } \\
\text { They were less sad, smiled } \\
\text { more and engaged in verbal } \\
\text { communication more after } \\
\text { the intervention increased. } \\
\mathrm{OP}=+\end{array}$ \\
\hline $\begin{array}{l}\text { Nurses' job } \\
\text { satisfaction }\end{array}$ & $\begin{array}{l}\text { - Education to enhance } \\
\text { nurses knowledge and skills } \\
\text { concerning person- } \\
\text { centered dementia care in } \\
\text { eight themes: Person- } \\
\text { centered care and demen- } \\
\text { tia, emotional impact of } \\
\text { caregiving, communication } \\
\text { in dementia, conflict man- } \\
\text { agement, challenging be- } \\
\text { haviours, teamwork, } \\
\text { environment and dementia, }\end{array}$ & $\begin{array}{l}\text { - Eight weekly session, } 90 \\
\text { min per time } \\
\text { - Three days after session, } \\
\text { individual sessions with } \\
\text { nurses }\end{array}$ & $\begin{array}{l}\text { Direct care workers stress, } \\
\text { burnout and job satisfaction } \\
\text { were assessed at } 2 \text { weeks } \\
\text { before and } 2 \text { weeks after the } \\
\text { intervention. }\end{array}$ & $\begin{array}{l}\text { OC: Continuing education } \\
\text { intervention has a significant } \\
\text { positive effect on nurses' } \\
\text { emotional exhaustion. } \\
\text { According to the qualitative } \\
\text { data, the experimental group } \\
\text { perceived enhanced } \\
\text { cohesion, emotional } \\
\text { management, and self-care } \\
\text { awareness. This can reduce } \\
\text { nurses' burnout. } \\
\mathrm{N}=+\end{array}$ \\
\hline
\end{tabular}

Source

Sposito

et al. [72],

2017

munication strategies, mulbaseline and after the eightweeks intervention through motor simulation, problem solving, relaxation and multisensory stimulation.

- Individual assisted sessions

for nurses by experts

- Supportive to improve nurses' ability to cope with job-related stress and burnout

- Knowledge transfer and skills training in focus on meetings

- on-the-job coaching included behavioral observation and direct feedback

- Person centered care group: two selected nurses per site engaged in off-site person-centered care education and after that person-centered care expert visited two full days on-site to assist these nurses to develop individual residents care plans and to implement personcentered care

- Dementia Care Mapping group: two selected nurses per site engaged in off-site dementia care mapping and person-centered care education and after that experts worked alongside them to conduct dementia care mapping for all participating residents.

\section{- $5 \times 3$-h team meetings - $3 \times 3$-h on-the-job coach- ing sessions}

- Person-centered care: 2-

Staff burnout, general wellday education off-site and 2-day on-site guide to implement person-centered care. Support by phone for 4 months.

- Dementia care mapping: 3day education off-site and alongside worked with selected nurses after the education. Support by phone for 4 months.
Veder Contact Methods effects to the caregivers' job satisfaction was assessed at baseline and after the 9 months intervention.
OC: The intervention had no significant effect for job satisfaction using the quantitative data findings. The qualitative data findings indicate that intervention has positive influence on the daily work performances of nursing home caregivers. $\mathrm{N}=0 /+$

P: Dementia care mapping was more effective than person-centered care to reduce the staff members' jobrelated burnout and emotional exhaustion. The support of managers is important. Without the managers support the influence of intervention is weaker and lasts less time.

S: There were no significant differences in terms of staff attitudes and reactions towards behavioral disturbances and care quality. $\mathrm{N}=+$
Barbosa et al. [47], 2015

Boersma et al. [49], 2017

Jeon et al. [65], 2012 
Table 2 Continuing education interventions, pedagogical methods, assessments, and their outcomes (Continued)

\begin{tabular}{|c|c|c|c|c|c|}
\hline Theme & Content of intervention & Pedagogical methods & Assessments & $\begin{array}{l}\text { Outcomes and } \\
\text { effectiveness in lens of } \\
\text { nurses, older people and } \\
\text { next of kin }\end{array}$ & Source \\
\hline \multirow[t]{5}{*}{$\begin{array}{l}\text { Nursing } \\
\text { activities }\end{array}$} & $\begin{array}{l}\text { - Knowledge-based seminar } \\
\text { material based on two } \\
\text { Swedish national docu- } \\
\text { mants about the key princi- } \\
\text { ples of palliative care. } \\
\text { - The Eductional booklet } \\
\text { used as study material with } \\
\text { nurses had five themes: } \\
\text { palliative care and dignified } \\
\text { care, next of kin, existence } \\
\text { and dying, symptom relief, } \\
\text { collaborative care. }\end{array}$ & $-5 \times 2 \mathrm{~h}$ education seminars & $\begin{array}{l}\text { Person-centeredness } \\
\text { education intervention } \\
\text { effectiveness on the staff's } \\
\text { perception of providing } \\
\text { person-centred palliative care } \\
\text { for older people in nursing } \\
\text { homes was assessed at base- } \\
\text { line and } 3 \text { months after the } \\
6 \text { months intervention. }\end{array}$ & $\begin{array}{l}\text { OC: The intervention was not } \\
\text { effective, because results } \\
\text { showed no improvement in } \\
\text { any outcomes. The only } \\
\text { perceived improvement area } \\
\text { in person-centered care was } \\
\text { the managers' and organiza- } \\
\text { tion's support of the staff's } \\
\text { everyday work to maintain } \\
\text { person-centered care. } \\
\mathrm{N}=0\end{array}$ & $\begin{array}{l}\text { Bökberg } \\
\text { et al. [50], } \\
2019\end{array}$ \\
\hline & $\begin{array}{l}\text { - Education about the } \\
\text { person-centered approach } \\
\text { to showering and and } \\
\text { towel baths focusing on } \\
\text { residents' needs, the ac- } \\
\text { commodation of residents' } \\
\text { preferences, attending to } \\
\text { the relationship and inter- } \\
\text { action with residents, using } \\
\text { effective communication } \\
\text { and interpersonal skills, } \\
\text { adapting the physical envir- } \\
\text { onment and bathing pro- } \\
\text { cedures to decrease } \\
\text { distress and discomfort. }\end{array}$ & $\begin{array}{l}\text { - } 2 \times 6 \text { weeks training } \\
\text { periods including didactic } \\
\text { sessions, reviewed } \\
\text { videotaped material, } \\
\text { coaching in bathing } \\
\text { situations by clinical nurse } \\
\text { specialist }\end{array}$ & $\begin{array}{l}\text { Effects of two bathing } \\
\text { interventions on caregiving } \\
\text { were assessed at baseline, } \\
\text { end of the first } 6 \text { weeks } \\
\text { intervention, and end of the } \\
\text { next } 6 \text { weeks intervention } \\
\text { also. }\end{array}$ & $\begin{array}{l}\text { OC: Bathing interventions } \\
\text { improved gentleness, verbal } \\
\text { support, confidence, and } \\
\text { ease, but not reduce the } \\
\text { hassles. } \\
\mathrm{N}=+ \\
\mathrm{OP}=+\end{array}$ & $\begin{array}{l}\text { Hoeffer } \\
\text { et al. [64], } \\
2006\end{array}$ \\
\hline & $\begin{array}{l}\text { - Developed from Kitwood's } \\
\text { model of Dementia and } \\
\text { framework for person- } \\
\text { centered care: understand- } \\
\text { ing dementia (the person } \\
\text { and disease), being with } \\
\text { the person who has de- } \\
\text { mentia, making a difference } \\
\text { in the life of the cognitively } \\
\text { impaired. }\end{array}$ & $\begin{array}{l}\text { - One } 2 \mathrm{~h} \text { and two 3-h lec- } \\
\text { tures with learning exer- } \\
\text { cises and role playing. } \\
\text { - On-site training twice per } \\
\text { week } \times 4 \text { weeks (total } 16 \mathrm{~h} \text { ) } \\
\text { - 4-h dementia care map- } \\
\text { ping session } \\
\text { - On-the-job practicing } \\
\text { - Consultation }\end{array}$ & $\begin{array}{l}\text { Sleeping of assisted living } \\
\text { residents with dementia was } \\
\text { assessed } 3 \text { days at baseline } \\
\text { and } 3 \text { days after the } \\
\text { intervention. }\end{array}$ & $\begin{array}{l}\text { P: Staff education } \\
\text { intervention may have } \\
\text { effective for improving the } \\
\text { sleep of residents with } \\
\text { dementia. In the intervention } \\
\text { group residents had } \\
\text { significantly more night-time } \\
\text { sleep and less daytime sleep } \\
\text { than in control group. } \\
\mathrm{OP}=+\end{array}$ & $\begin{array}{l}\text { Li et al. [66], } \\
2017\end{array}$ \\
\hline & $\begin{array}{l}\text { - Oral pathology, dementia } \\
\text { care, individualized care } \\
\text { planning and skills training }\end{array}$ & $\begin{array}{l}\text { - Seminars } \\
\text { - On-site training daily for } 2 \\
\text { weeks by dental hygienist } \\
\text { and geriatric psychologist } \\
\text { - Consultation. }\end{array}$ & $\begin{array}{l}\text { Residents' oral hygiene were } \\
\text { assessed at baseline via } \\
\text { videotaped performing } \\
\text { mouth care by CNAs and } \\
\text { during the } 6 \text { weeks } \\
\text { intervention by } \\
\text { measurements and video } \\
\text { recording by CNAs. }\end{array}$ & $\begin{array}{l}\text { P: The intervention had a } \\
\text { significant effect on the } \\
\text { residents' oral hygiene } \\
\text { outcomes as Plaque Index } \\
\text { and Gingival Index. } \\
\text { S: after the intervention } \\
\text { mouth care was more } \\
\text { thorough, took more time } \\
\text { and consistency of care } \\
\text { appeared to be } \\
\text { more important for natural } \\
\text { teeth than dentures. } \\
\mathrm{OP}=+\end{array}$ & $\begin{array}{l}\text { Sloane et al. } \\
{[70]} \\
2013\end{array}$ \\
\hline & $\begin{array}{l}\text { - Person-centered bathing } \\
\text { focused on resident com- } \\
\text { fort and preferences, } \\
\text { viewed behavioral symp- } \\
\text { toms as expressions of un- } \\
\text { met needs, employed } \\
\text { communication techniques } \\
\text { appropriate for the resi- } \\
\text { dent's disease severity, ap- } \\
\text { plied problem-solving } \\
\text { approaches to identify } \\
\text { causes and potential solu- } \\
\text { tions and regulated the }\end{array}$ & $\begin{array}{l}-2 \times 6 \text { weeks training } \\
\text { periods including didactic } \\
\text { sessions, reviewed } \\
\text { videotaped material, } \\
\text { coaching in bathing } \\
\text { situations by clinical nurse } \\
\text { specialist }\end{array}$ & $\begin{array}{l}\text { Nonpharmacological } \\
\text { techniques in reducing } \\
\text { agitation, aggression and } \\
\text { discomfort in nursing home } \\
\text { residents with dementia in } \\
\text { bathing situations and skin } \\
\text { condition were assessed at } \\
\text { baseline and end of both } \\
\text { intervention periods. }\end{array}$ & $\begin{array}{l}\text { P: Person-centered shower- } \\
\text { ing and the towel bath con- } \\
\text { stitute safe, effective } \\
\text { methods of reducing agita- } \\
\text { tion, aggression, and discom- } \\
\text { fort during bathing of } \\
\text { people with dementia. } \\
\text { S: Average bath duration } \\
\text { increased significantly in } \\
\text { showering. Neither } \\
\text { intervention resulted in } \\
\text { fewer body parts being } \\
\text { bathed, both improved skin }\end{array}$ & $\begin{array}{l}\text { Sloane et al. } \\
{[71]} \\
2004\end{array}$ \\
\hline
\end{tabular}


Table 2 Continuing education interventions, pedagogical methods, assessments, and their outcomes (Continued)

\begin{tabular}{|c|c|c|c|c|c|}
\hline Theme & Content of intervention & Pedagogical methods & Assessments & $\begin{array}{l}\text { Outcomes and } \\
\text { effectiveness in lens of } \\
\text { nurses, older people and } \\
\text { next of kin }\end{array}$ & Source \\
\hline & $\begin{array}{l}\text { physical environment to } \\
\text { maximize resident comfort. }\end{array}$ & & & $\begin{array}{l}\text { condition. } \\
\mathrm{N}=+ \\
\mathrm{OP}=+\end{array}$ & \\
\hline \multirow[t]{3}{*}{$\begin{array}{l}\text { Older } \\
\text { peoples' } \\
\text { quality of } \\
\text { life }\end{array}$} & $\begin{array}{l}\text { - Person-centered care: resi- } \\
\text { dents' feelings when agi- } \\
\text { tated, interacting with } \\
\text { residents in a person- } \\
\text { centered way and using } \\
\text { Person-centered care plan- } \\
\text { ning to meet the residents' } \\
\text { psychosocial needs. } \\
\text { - Person-centered education: } \\
\text { improvements to the safety } \\
\text { accessibility and utility of } \\
\text { outdoor spaces, provision } \\
\text { of a greater variety of social } \\
\text { spaces and using colour } \\
\text { and objects for wayfinding } \\
\text { and to improve feelings of } \\
\text { familiarity. }\end{array}$ & $\begin{array}{l}\text { - Person-centered care: } 32 \mathrm{~h} \\
\text { off-site education for" Key" } \\
\text { nurses and on-site supervi- } \\
\text { sion (range } 2-16 \text { h) and } \\
\text { support by phone. }\end{array}$ & $\begin{array}{l}\text { Difference effects of PCC and } \\
\text { PCE interventions were } \\
\text { assessed at baseline, after } 4 \\
\text { months intervention and at } \\
8 \text { months follow-up. }\end{array}$ & $\begin{array}{l}\text { P: Person-centered care and } \\
\text { person-centered education } \\
\text { interventions together did } \\
\text { not seem to improve the } \\
\text { quality of life or reduce agi- } \\
\text { tation but improved emo- } \\
\text { tional responses to care. } \\
\text { Depression scores did not } \\
\text { change in any of the groups. } \\
\text { S: Education interventions } \\
\text { together seems to improve } \\
\text { in care interaction quality. } \\
\mathrm{OP}=0\end{array}$ & $\begin{array}{l}\text { Chenoweth } \\
\text { et al. [53], } \\
2014\end{array}$ \\
\hline & $\begin{array}{l}\text { - An understanding that } \\
\text { behaviour is a form of } \\
\text { communication. Nurses } \\
\text { need to recognize that } \\
\text { feelings persist despite } \\
\text { cognitive impairment and } \\
\text { acknowledge feelings } \\
\text { during social interactions. } \\
\text { Nurses should focus on the } \\
\text { unique way that residents } \\
\text { express feelings and needs } \\
\text { to change usual care. }\end{array}$ & $\begin{array}{l}\text { - Person-centered care: 2- } \\
\text { day training sessions for } \\
\text { two nurses per site } \\
\text { - Two visits per site } \\
\text { - Dementia care mapping: } 2 \\
\text { X } 6 \text { h training for two } \\
\text { nurses per site } \\
\text { - Both: on-site assisting to } \\
\text { implement dementia care } \\
\text { mapping/person-centered } \\
\text { care for residents and sup- } \\
\text { port by phone }\end{array}$ & $\begin{array}{l}\text { Comparison of person- } \\
\text { centred care, dementia care } \\
\text { mapping and usual care ef- } \\
\text { fects to agitation and psychi- } \\
\text { atric symptoms were } \\
\text { assessed at baseline, after } 4 \\
\text { months intervention and at } \\
4 \text { months of follow-up. }\end{array}$ & $\begin{array}{l}\text { P: Both person-centered care } \\
\text { and dementia care mapping } \\
\text { seems to reduce agitation. } \\
\text { S: Person-centered care was } \\
\text { less safe than dementia care } \\
\text { mapping, because falls hap- } \\
\text { pened more in person- } \\
\text { centered care groups. } \\
\text { Person-centered care had } \\
\text { more positive social and care } \\
\text { interactions than other } \\
\text { groups. Interventions did not } \\
\text { have any influence on the } \\
\text { level of medication use. } \\
\text { Person-centered care inter- } \\
\text { vention costs were lower } \\
\text { than dementia care } \\
\text { mapping. } \\
\text { OP =+ }\end{array}$ & $\begin{array}{l}\text { Chenoweth } \\
\text { et al. [56], } \\
2009\end{array}$ \\
\hline & $\begin{array}{l}\text { - The concept of dementia; } \\
\text { how to respond to } \\
\text { dementia; the concept of } \\
\text { person-centered care; and } \\
\text { specific methods of inter- } \\
\text { acting with residents with } \\
\text { dementia. } \\
\text { - Discussions, based on the } \\
\text { dementia care mapping } \\
\text { results, focused on the } \\
\text { following: consideration of } \\
\text { the behaviors of residents } \\
\text { with dementia; respecting } \\
\text { residents during } \\
\text { interactions; and improving } \\
\text { future care processes. }\end{array}$ & $\begin{array}{l}-3 \times 60-90 \text { min training } \\
\text { sessions }\end{array}$ & $\begin{array}{l}\text { Effects of staff training on } \\
\text { person-centred care and de- } \\
\text { mentia care mapping on } \\
\text { quality of life of residents } \\
\text { with dementia were assessed } \\
\text { at } 1 \text { month before baseline, } \\
\text { at baseline and last after the } \\
\text { intervention. }\end{array}$ & $\begin{array}{l}\text { OC: Person-centered care- } \\
\text { based staff training, and de- } \\
\text { mentia care mapping could } \\
\text { effectively improve the qual- } \\
\text { ity of life of residents with } \\
\text { dementia. } \\
\text { OP }=+\end{array}$ & $\begin{array}{l}\text { Yasuda \& } \\
\text { Sakakibara } \\
{[75], 2017}\end{array}$ \\
\hline
\end{tabular}

$N$ Nurses, OP Older People, NK Next of Kin, + positive effect, $O$ non effect, $P$ Primary outcome, $S$ Secondary outcome, OC Outcome, if the authors did not discriminate between primary and secondary outcomes

centered care [14]. In one study, the continuing education intervention, delivered using a digital device, reported improved sleep for residents with dementia. The experimental group of residents had significantly more nighttime sleep $(p=0.03)$ and less daytime sleep $(p=$ 0.01 ) in the post test [66]. Nursing activities such as 
bathing [64]; reduced agitation, aggression, and discomfort in persons with dementia [71] and oral hygiene [70] had a positive influence.

The quality of life of older people themed continuing education interventions outcomes varied. In some studies, there was no effect on the quality of residents life [53] but in another study the intervention has got effectiveness to the residents' quality of life [75]. On these quality-of-life continuing education interventions is usually compared different education methods as personcentered care and Dementia Care Mapping [56].

\section{Instruments used in continuing education interventions}

Although all reviewed studies included person-centered care within the educational intervention, only one study [50] used a validated person-centered care instrument to measure person-centered care outcomes. The PersonCentered Environment and Care Assessment Tool was also used, but its validity is difficult to evaluate as it is within an unpublished $\mathrm{PhD}$ thesis [54]. The most commonly used quantitative instruments were, the CohenMansfield Agitation Inventory [40] $(n=7)$, and the Maslach Burnout Inventory [59] $(n=4)$ (Table 1$)$.

\section{Discussion}

This study aimed to analyze and synthesize the existing research literature about person-centered care-based continuing educational interventions for nurses working in long-term care settings for older people. The analysis revealed the focus of this continuing education is on: older people's medication; the interaction and caring culture; nurses' job satisfaction; nursing activities and older people's quality of life. Much of the delivery of this continuing educational training used behaviorist, using pedagogical methods such as lectures and seminars. The method of delivery of education can have an influence on the effectiveness of the intervention [38, 42], but it may be useful to use more learner-centered approaches to improve outcomes in future research [76]. The outcomes of the continuing education interventions of person-centered care were largely collected e.g. from nurses $[42,48,50]$ observation of older people or e.g. from older people's documents [36, 38, 68]. It may be useful, if data on outcomes were also routinely collected from older people and their next of kin [77].

The content of the continuing education activities included person-centered care elements that were designed to influence the interactions between the residents and nurses, and through this, the care environment. However, the influence of continuing education on person-centered care was measured in only one study [50]. Differences in the type of design, outcomes, number of participants, and duration of continuing education intervention hindered study comparisons and generalizations. Moreover, a range of methodological weakness made it difficult to provide any conclusive indication about the effectiveness of these approaches. This heterogeneity of the background theories and measurements of the continuing education interventions used in the studies reviewed, gives the impression of conceptual imprecision. Other researchers support this view [26] thought there is evidence that theory-based educational interventions are effective [78]. Although personcentered care is an abstract concept and so difficult to measure, the creation of a stronger argument for its use requires more rigorous research including the wider use of valid, person-centered care measurement instruments.

Pedagogical methods were at the core of the effectiveness of the continuing education interventions. Some of the studies educated "key nurses," leaving these nurses to help other nurses learn to implement change in their workplace $[50,53,56,61]$. There are some risks associated with using "key nurses" in this way, as the process of implementing person centered care requires an understanding of the origin and content of the concepts alongside the practical uses in care situations. The work environment, level of job satisfaction, managerial approaches and the personalities of nurses can help or hinder the work of these "key nurses", who will require stronger managerial support, encouraging flexible working practices and the involvement of nurses in care decisions [53]. Earlier studies have reported that the collective competence of a team is greater than one persons' competence [21]. Studies in this review using "key nurses" to introduce person-centered care were not effective in developing the collective competence of the nursing teams directly, limiting the possible benefits of the education e.g. [50].

When introducing person-centered care, pedagogical methods such as face-to-face teaching, though important, were not seen to be sufficient generally [36] and most of the interventions in this review used additional on-site support and consultation e.g. [42, 48, 68, 70] video material e.g. [57, 61, 74] brainstorming [72] and role-playing $[68,72]$ to achieve their preferred outcomes. Additionally, more student-centered approaches such as simulation-based nursing education interventions have been shown to improve critical and creative thinking [79] though simulation was only used in one reviewed study [72].

Digitalization as part a pedagogical method can support learning activities [80, 81]. Appropriate applications including learner-centered approaches, improve communication between students and educators and enable a collaborative learning environment [82]. However, use of these digital platforms have strengths and weaknesses. It has been reported that Moodle promotes professionalism, ethical behavior and develops critical thinking, but the use of other participatory web-based platforms, 
including social media platforms may suffer from credibility of information and are open to student misinterpretation [83]. The choice of appropriate platform requires some competence [80].

In this review, after the continuing education, nurses: increased the number of positive interactions with residents [38], improved person-centered care delivery [42], communication [44], and satisfaction in relationship with older people $[46,57]$, and increased their knowledge about meeting the needs of people with dementia [69]. Other improvements delivered by the outcomes of the reviewed studies were: a reduction in the use of medicines [36, 73]; improved behavioral symptoms $[38,56,62,69,71]$ and relationships with nurses $[57,64,72,74]$ improved the quality of life for the older people [48, 67, 75]; and increased the number of support for daily activities $[66,70]$. These results demonstrate the usefulness of research of continuing education interventions, especially when these changes have been brought about in work practice: reduce nurses burnout $[46,47,65]$ have positive effects on nurses mood and burden [67]; and influence organizational culture, changing nurses experiences for the better $[48,69]$. This general increase in the quality of care and care environment after suitable continuing education is also supported by other evidence [17].

The data that informed the research came from: residents' medication charts; nurse-completed questionnaires; video recordings and from observation. In only one study did researchers collect data from the next of kin, about person-centered care interventions [69]. This is disappointing as the opinions of the older people and their next of kin on the results of the continuing education intervention might facilitate a better understanding of the interventions that meet their needs. The lack of old people's and their next of kin views and perceptions need to be addressed in future research.

Most of the interventions used, produced the positive outcomes described above. However, in some studies the sample sizes were quite small and not power analyzed e.g. $[42,57,75]$. In other studies the content or delivery of the intervention may not have been appropriate [50, 61, 68]. Many other weaknesses were described in the studies reviewed. Additionally, the drop-out rate from the research may have been a major difficulty $[48,50]$. This drop-out occurs, for example through the mortality of the residents, and nursing staff turnover [84, 85]. Four studies did not report any positive outcomes from the continuing education interventions $[50,55,61,68]$. There were quite several studies that did not follow the reporting guidelines, in which case the primary and secondary measures and outcomes were not clearly mentioned [42, 44, 46-50, 57, 61, 63, 64, 67, 69, 74, 75].
This review has identified and analyzed the available continuing education interventions about personcentered nursing in studies from many different countries. Overall, the studies are difficult to evaluate thoroughly often lacking rigorous conceptual and theory bases. This situation could be improved by careful design, choice of research settings, and strict protocols designed to provide robust evidence about the effectiveness of continuing education interventions.

\section{Strengths and limitations}

This review has some strengths. Firstly, this review focused on all research-based continuing education interventions about person-centered care, targeting nurses in older people's long-term care. The review sought literature from five relevant databases without time limits to provide the best opportunity to find as much of the relevant literature as possible. Using the inclusion criteria, the review considered all available experimental designs, randomized controlled trials alongside those with no control group. This approach facilitated the capture of the widest variety of continuing education intervention studies in this field [86, 87].

The computerized search from databases was conducted by one researcher with the support of an information specialist and then determined by research group.

Secondly, we used the whole research team to assist with study selection, reducing selection bias through discussion towards consensus. For example, in step one (Fig. 1) the citations were evaluated by two researchers first independently and then together. Where consensus was not found a third opinion was sought from another member of the research group.

The limitations of the review relate to the quality of the available studies, limited language only in English and unpublished studies. The research quality appraisal was challenging, because of the limitations of the study designs or number of participants, even though the quality score averaged 7.70 out of 9 [34]. Statistically, the meta-analysis was not applicable because the interventions were different in content and the outcome variables were not comparable [86].

\section{Conclusion}

This review enhances the understanding about personcentered care-based continuing education interventions for nurses working in long-term care settings for older people. Firstly, we identified five themes describing the contents of this type of continuing education. However, concept person-centered care is used in quite different ways and the use of stronger theory-based interventions which can be measured with validated person-centered care instruments is still required. Secondly, we identified 
the pedagogical methods which were used in these continuing education interventions about person-centered care. Pedagogical methods are quite traditional and could be enhanced using more learner-centered approaches such as appropriate simulation, digital platforms and social media which were not used sufficiently in the reviewed studies. Thirdly, we found that the evaluation of the results of continuing education interventions were mainly conducted from a nurse's perspective, through for example, medication charts or by qualitative methods such as observation. The perspective of the older person and their next of kin was not evident and should be taken into consideration in future research.

Continuing educational interventions for nurses working in long-term care settings for older people need to be further developed to strengthen nurse's competence in person-centered care. The positive outcomes in the five themes identified in this review improve the quality of older people's long-term care. More empirical research-based continuing education interventions are needed, that include a wider set of learner-centered pedagogical methods with measurable outcomes which consider the opinions of older people and their next of kin. These measurable outcomes should be quantified using validated instruments. These developments are important for the quality of care delivery, the quality of life of older people in care and nurses job satisfaction.

\section{Abbreviations \\ CINAHL: Cumulative index to nursing and allied health literature; PsycINFO: A world-class resource for abstracts and citations of behavioral and social sci- ence research; ERIC: Education resources information center; PRIS MA: Preferred reporting items for systematic reviews and meta-analysis: RCT: Randomized controlled trial; CCT: Controlled clinical trial; JBI: The Joanna Briggs Institute checklist for quasi-experimental studies; N: Nurse; NK: Next of kin; OP: Older people; +: A positive effect of the intervention; 0: Non effect of the intervention; P: Primary outcome; S: Secondary outcome; OC: Outcome; E: Experimental group; C: Control group; A: All participants; PCC: Person- centered care; PCE: Person-centered environment; DCM: Dementia care mapping}

\section{Acknowledgements}

We would like to thank Dr. Norman Rickard RN PhD for his help with the English language.

\section{Authors' contributions}

All authors have read and approved the final manuscript. The conception and design of the study: MP, MS, RS. Acquisition of data: MP, MS, RS. Analysis and interpretation of data: MP, MS, RS. Drafting the article: MP, MS, AC, RS. Revising it critically for important intellectual content: MP, MS, AC, RS.

\section{Funding}

The authors have no external funding to declare.

\section{Availability of data and materials}

The dataset from this study is available from the corresponding author upon reasonable request.

\section{Declarations}

Ethics approval and consent to participate

Not applicable

\section{Consent for publication}

Not applicable

\section{Competing interests}

Neither this manuscript nor one with substantially similar content under our authorship has been published or is being considered for publication elsewhere. The authors declare that there is no conflict of interest.

\section{Author details}

'Department of Nursing Science, University of Turku, Turku, Finland. 2Department of Nursing Science, Cyprus University of Technology, Limassol, Cyprus. ${ }^{3}$ Turku University Hospital, Turku, Finland. ${ }^{4}$ City of Turku, Welfare Division, Turku, Finland.

Received: 17 September 2020 Accepted: 15 April 2021

Published online: 28 April 2021

\section{References}

1. Guzman, J., Pawliczko, A., Beales, S., \& Voelcker, I.. Overview of available policies and legislation, data and research, and institutional arrangements relating to older persons - progress since Madrid. 2012. Retrieved from https://www.unfpa.org/sites/default/files/pub-pdf/Older_Persons_Report.pdf.

2. Wynne, M.. Office of Nursing and Midwifery Services Director Quality CareMetrics Project Group. National guideline for nursing and midwifery quality care-metrics data measurement in older person services. 2018. Retrieved from https://www.hse.ie/eng/services/publications/ nursingmidwiferyservices/national-guideline-qcm-older-persons.pdf.

3. NICE. National institute for health and care excellence. Older people with social care needs and multiple long - term conditions, October; 2015. p. 1166. Retrieved from https://www.nice.org.uk/guidance/ng22/evidence/fullguideline-552742669

4. WHO. Global strategy on people-centred and integrated health services 2015. Retrieved from http://apps.who.int/iris/bitstream/10665/155002/1/ WHO_HIS_SDS_2015.6_eng.pdf\%0A. http://www.who.int/servicedeliverysa fety/areas/people-centred-care/global-strategy/en/

5. Zahedi F, Sanjari M, Aala M, Peymani M, Aramesh K, Parsapour A, et al. The code of ethics for nurses. Iran J Public Health. 2013:42(1):1-8.

6. ICN. The ICN code of ethics for nurses. Int Counc Nurs. 2012;8 Retrieved from https://www.icn.ch/sites/default/files/inline-files/2012_ICN_ Codeofethicsfornurses_eng.pdf. Accessed 22 Apr 2021.

7. Ministry of Social Affairs and Health. Quality recommendation to guarantee a good quality of life and improved services for older persons 2017-2019. Publications of the Ministry of Social Affairs and Health 1/2018. 2018. Retrieved from http://urn.fi/URN:ISBN:978-952-00-3906-6

8. Finlex 980/2012. Act on supporting the functional capacity of the older population and on social and health care services for older persons. Retrieved from https://www.finlex.fi/fi/laki/kaannokset/2012/en20120980_2 0120980.pdf. Accessed 22 Apr 2021.

9. Kitwood T, Bredin K. Towards a theory of dementia care: personhood and well-being. Ageing Soc. 1992;12:269-87 Retrieved from http://www.ncbi. nlm.nih.gov/pubmed/11654434.

10. Rogers, Carl R. by Introduction by Peter, D., Kramer, M. D. On becoming a person. New York: Houghton Mifflin Company; 1995.

11. Suhonen $\mathrm{R}$, Charalambous $\mathrm{A}$. The concept of individualized care. In: Suhonen R, Stolt M, Papastavrou E, editors. Individualized care theory, measurement, research and practice: Springer International Publishing; 2018. p. 27-38. https://doi.org/10.1007/978-3-319-89899-5.

12. Nolan MR, Davies S, Brown J, Keady J, Nolan J. Beyond "person-centred" care: a new vision for gerontological nursing. J Clin Nurs. 2004;13(s1):45-53 https://doi.org/10.1111/j.1365-2702.2004.00926.x.

13. Morgan S, Yoder LH. A concept analysis of person-centered care. J Holist Nurs. 2012;30(1):6-15 https://doi.org/10.1177/0898010111412189.

14. Håkansson Eklund J, Holmström IK, Kumlin T, Kaminsky E, Skoglund K, Höglander J, et al. "Same same or different?" a review of reviews of personcentered and patient-centered care. Patient Educ Couns. 2019;102(1):3-11 https://doi.org/10.1016/j.pec.2018.08.029. 
15. Zhao J, Gao S, Wang J, Liu X, Hao Y. Differentiation between two healthcare concepts: person-centered and patient-centered care. Int J Nurs Sci. 2016; 3(4):398-402 https://doi.org/10.1016/j.jinss.2016.08.009.

16. Terada S, Oshima E, Yokota O, Ikeda C, Nagao S, Takeda N, et al. Personcentered care and quality of life of patients with dementia in long-term care facilities. Psychiatry Res. 2013;205(1-2):103-8 https://doi.org/10.1016/j. psychres.2012.08.028.

17. Edvardsson D, Watt E, Pearce F. Patient experiences of caring and personcentredness are associated with perceived nursing care quality. J Adv Nurs. 2017;73(1):217-27 https://doi.org/10.1111/jan.13105.

18. Ministry of Education and Culture. Vocabulary of education: Publications of the Ministry of Education and Culture, Finland; 2018. p. 22, 166. Retrieved from http://urn.fi/URN:ISBN:978-952-263-571-6

19. Gallagher L. Continuing education in nursing: a concept analysis. Nurse Educ Today. 2007;27(5):466-73 https://doi.org/10.1016/j.nedt.2006.08.007.

20. Meretoja R, Leino-Kilpi H, Kaira AM. Comparison of nurse competence in different hospital work environments. J Nurs Manag. 2004;12(5):329-36 https://doi.org/10.1111/j.1365-2834.2004.00422.x.

21. Bing-Jonsson PC, Hofoss D, Kirkevold M, Bjørk IT, Foss C. Sufficient competence in community elderly care? Results from a competence measurement of nursing staff. BMC Nurs. 2016;15(5):1-11 https://doi.org/1 0.1186/s12912-016-0124-z.

22. Suhonen R, Gustafsson M-L, Katajisto J, Välimäki M, Leino-Kilpi H. Nurses' perceptions of individualized care. J Adv Nurs. 2010;66(5):1035-46 https:// doi.org/10.1111/j.1365-2648.2009.05256.x.

23. Glerean N, Hupli M, Talman K, Haavisto E. Young peoples' perceptions of the nursing profession: an integrative review. Nurse Educ Today. 2017;57: 95-102 https://doi.org/10.1016/j.nedt.2017.07.008.

24. Sandberg L, Borell L, Edvardsson D, Rosenberg L, Boström AM. Job strain: a cross-sectional survey of dementia care specialists and other staff in Swedish home care services. J Multidiscip Healthc. 2018;11:255-66 https:// doi.org/10.2147/JMDH.S155467.

25. Suhonen R, Alikleemola P, Katajisto J, Leino-Kilpi H. Nurses' assessments of individualised care in long-term care institutions. J Clin Nurs. 2012;21(7-8): 1178-88 https://doi.org/10.1111/j.1365-2702.2011.03855.x.

26. Barbosa A, Sousa L, Nolan M, Figueiredo D. Effects of person-centered care approaches to dementia care on staff. Am J Alzheimers Dis Other Dement. 2015;30(8):713-22 https://doi.org/10.1177/1533317513520213.

27. Brownie S, Nancarrow S. Effects of person-centered care on residents and staff in aged-care facilities: a systematic review. Clin Interv Aging. 2013;8:110 https://doi.org/10.2147/CIA.S38589.

28. Blake D, Berry K, Brown LJE. A systematic review of the impact of personcentred care interventions on the behaviour of staff working in dementia care. J Adv Nurs. 2020;76(2):426-44 https://doi.org/10.1111/jan.14251.

29. UN. United Nations, Department of Economic and Social Affairs. World Population Prospects 2019: Highlights. New York: UN; 2019. p. 2-3. Retrieved from http://www.ncbi.nlm.nih.gov/pubmed/12283219

30. WHO. Global health and aging: National Institute on Aging, National Institutes of Health, U.S. Department of Health and Human Services; 2012. Retrieved from https://www.who.int/ageing/publications/global_health.pdf

31. Harris JD, Quatman CE, Manring MM, Siston RA, Flanigan DC. How to write a systematic review. Am J Sports Med. 2014;42(11):2761-8 https://doi.org/1 $0.1177 / 0363546513497567$.

32. Allea. ALLEA. The European code of conduct for research integrity. 2017. Retrieved from https://www.allea.org/wp-content/uploads/2017/05/ALLEAEuropean-Code-of-Conduct-for-Research-Integrity-2017.pdf

33. Moher D, Liberati A, Tetzlaff J, Altman DG. Preferred reporting items for systematic reviews and meta-analyses: the PRISMA statement. J Clin Epidemiol. 2009;62(10):1006-12 https://doi.org/10.1016/j.jclinepi.2009.06.005.

34. Joanna Briggs Institute. Checklist for quasi-experimental studies. 2017. https://joannabriggs.org/sites/default/files/2020-08/Checklist_for_QuasiExperimental_Appraisal_Tool.pdf

35. Hsieh HF, Shannon SE. Three approaches to qualitative content analysis. Qual Health Res. 2005;15(9):1277-88 https://doi.org/10.1177/10497323052 76687.

36. Azermai M, Wauters $M$, De Meester $D$, Renson L, Pauwels D, Peeters L, et al. A quality improvement initiative on the use of psychotropic drugs in nursing homes in Flanders. Acta Clin Belg. 2017;72(3):163-71 https://doi. org/10.1080/17843286.2017.1287230.

37. Wauters M, Azermai M, Perehudoff $K$, Versluys $K$, Steeman E, Petrovic M Development and validation of the psychotropic education and knowledge
(PEAK) test on psychotropic drugs for nurses in an acute geriatric care setting. Eur Geriatr Med. 2016;7(2):135-41 https://doi.org/10.1016/j.eurger.2 016.02.002.

38. Ballard C, Corbett A, Orrell M, Williams G, Moniz-Cook E, Romeo R, et al. Impact of person-centred care training and person-centred activities on quality of life, agitation, and antipsychotic use in people with dementia living in nursing homes: a cluster-randomised controlled trial. PLoS Med. 2018;15(2):1-18 https://doi.org/10.1371/journal.pmed.1002500.

39. Mulhern B, Rowen D, Brazier J, Smith S, Romeo R, Tait R, et al. Development of DEMQOL-U and DEMQOL-PROXY-U: generation of preference-based indices from DEMQOL and DEMQOL-PROXY for use in economic evaluation. Health Technol Assess. 2013;17(5):1-160 https://doi.org/10.3310/hta17050.

40. Cohen-Mansfield J. Measurement of inappropriate behavior associated with dementia. J Gerontol Nurs. 1999;25(2):42-51 https://doi.org/10.3928/00989134-19990201-08.

41. Wood S, Cummings JL, Hsu MA, Barclay T, Wheatley MV, Yarema KT, et al. The use of the neuropsychiatric inventory in nursing home residents: characterization and measurement. Am J Geriatr Psychiatr. 2000;8(1):75-83 https://doi.org/10.1097/00019442-200002000-00010.

42. Barbosa A, Nolan M, Sousa L, Figueiredo D. Person-centredness in direct care workers caring for residents with dementia: effects of a psychoeducational intervention. Dementia. 2017;16(2):192-203 https://doi.org/10.11 77/1471301215585667.

43. Grosch K, Medvene L, Wolcott H. Person-centered caregiving instruction for geriatric nursing assistant students: development and evaluation. J Gerontol Nurs. 2008;34(8):23-31 https://doi.org/10.3928/00989134-20080801-07.

44. Barbosa A, Marques A, Sousa L, Nolan M, Figueiredo D. Effects of a psychoeducational intervention on direct care workers' communicative behaviors with residents with dementia. Health Commun. 2016;31(4):453-9 https://doi. org/10.1080/10410236.2014.965382.

45. Kitwood T. Toward a theory of dementia care: ethics and interaction. J Clin Ethics. 1998;9(1):23-34 Retrieved from http://www.ncbi.nlm.nih.gov/ pubmed/9598430

46. Barbosa A, Nolan M, Sousa L, Marques A, Fiqueiredo D. Effects of a psychoeducational intervention for direct care workers caring for people with dementia. Am J Alzheimers Dis Other Dement. 2016:31(2):144-55 https://doi.org/10.1177/1533317515603500.

47. Barbosa A, Nolan M, Sousa L, Fiqueiredo D. Supporting direct care workers in dementia care: effects of a psychoeducational intervention. Am J Alzheimers Dis Other Dement. 2015;30(2):130-8 https://doi.org/10.1177/1 533317514550331.

48. Boersma $\mathrm{P}$, van Weert JCM, Lissenberg-Witte BI, van Meijel B, Dröes R-M. Testing the implementation of the Verder contact method: a theathrebased communication method in dementia care. The Gerontologist. 2019; 59(4):780-91 https://doi.org/10.1093/geront/gnx200.

49. Boersma P, Droandes RM, Lissenberg-Witte BI, Van Meijel B, Van Weert JCM. Does working with the veder contact method influence the job satisfaction of caregivers? A non-randomized controlled trial in nursing homes for people with dementia. Int Psychogeriatr. 2017;29(12):2017-32 https://doi. org/10.1017/S1041610217001582.

50. Bökberg C, Behm L, Wallerstedt B, Ahlström G. Evaluation of personcenteredness in nursing homes after a palliative care intervention: pre- and post-test experimental design. BMC Palliat Care. 2019;18(44):1-10 https://doi. org/10.1186/s12904-019-0431-8.

51. Edvardsson D, Fetherstonhaugh D, Nay R, Gibson S. Development and initial testing of the person-centered care assessment tool (P-CAT). Int Psychogeriatr. 2010;22(1):101-8 https://doi.org/10.1017/S1041610209990688.

52. Edvardsson D, Sandman PO, Rasmussen B. Construction and psychometric evaluation of the Swedish language person-centred climate questionnaire staff version. J Nurs Manag. 2009;17(7):790-5 https://doi.org/10.1111/j.1365-2 834.2009.01005.x.

53. Chenoweth L, Forbes I, Fleming R, King MT, Stein-Parbury J, Luscombe G, et al. PerCEN: a cluster randomized controlled trial of person-centered residential care and environment for people with dementia. Int Psychogeriatr. 2014;26(7): 1147-60 https://doi.org/10.1017/S1041610214000398.

54. Chenoweth L, King M, Luscombe G, Forbes I, Jeon YH, Parbury JS, et al. Study protocol of a randomised controlled group trial of client and care outcomes in the residential dementia care setting. Worldviews Evid-Based Nurs. 2011;8(3):153-65 https://doi.org/10.1111/j.1741-6787.2010.00204.x.

55. Smith SC, Lamping DL, Banerjee S, Harwood R, Foley B, Smith P, et al. Measurement of health-related quality of life for people with dementia. 
Heal Technol. 2005;9(10):1-93 Retrieved from http://www.ncbinlm.nih.gov/ pubmed/15774233.

56. Chenoweth L, King MT, Jeon Y-H, Brodaty H, Stein-Parbury J, Norman R, et al. Articles Caring for Aged Dementia Care Resident Study (CADRES) of person-centred care, dementia-care mapping, and usual care in dementia: a cluster-randomised trial. Lancet Neurol. 2009;8(4):317-25. https://doi.org/10.1 016/S1474.

57. Coleman CK, Medvene LJ. A person-centered care intervention for geriatric certified nursing assistants. Gerontologist. 2013;53(4):687-98 https://doi. org/10.1093/geront/gns135.

58. Lann-Wolcott $H$, Medvene $L$, Williams K. Measuring the personcenteredness of caregivers working with nursing home residents with dementia. Behav Ther. 2011;42(1):89-99 https://doi.org/10.1016/j.beth.2010. 02.005 .

59. Maslach C, Schaufeli WB, Leiter MP. Job Burnout. Annu Rev Psychol. 2001; 52(1):397-422. https://doi.org/10.1146/annurev.psych.52.1.397.

60. Heliker D, Nguyen HT. Story sharing: enhancing nurse aide-resident relationships in long-term care. Res Gerontol Nurs. 2010;3(4):240-52 https:// doi.org/10.3928/19404921-20100303-01.

61. Cornelison LJ, Hermer L, Syme ML, Doll G. Initiating Aha moments when implementing person-centered care in nursing homes: a multi-arm, prepost intervention. BMC Geriatr. 2019;19(115):1-11 https://doi.org/10.1186/ s12877-019-1121-3.

62. Fossey J, Ballard C, Juszczak E, James I, Alder N, Jacoby R, et al. Effect of enhanced psychosocial care on antipsychotic use in nursing home residents with severe dementia: cluster randomised trial. Br Med J. 2006; 332(7544):756-8. https://doi.org/10.1136/bmj.38782.575868.7C. https://doi. org/10.1136/bmj.38782.575868.7C.

63. Gillis K, Lahaye H, Stijn D, Lips D, Arnouts H, Van Bogaert P. A personcentred team approach targeting agitated and aggressive behaviour amongst nursing home residents with dementia using the senses framework. Int J Older People Nursing. 2019;14(4):e12269. https://doi.org/1 0.1111/opn.12269.

64. Hoeffer B, Talerico KA, Rasin J, Mitchell CM, Stewart BJ, Mckenzie D, et al. Assisting cognitively impaired nursing home residents with bathing: effects of two bathing interventions on caregiving. The Gerontologist. 2006:46(4): 524-32 https://doi-org.ezproxy.utu.fi/10.1093/geront/46.4.524.

65. Jeon YH, Luscombe G, Chenoweth L, Stein-Parbury J, Brodaty H, King M, et al. Staff outcomes from the Caring for Aged Dementia Care REsident Study (CADRES): a cluster randomised trial. Int J Nurs Stud. 2012;49(5):50818 https://doi.org/10.1016/j.jpurstu.2011.10.020.

66. Li J, Grandner MA, Chang Y-P, Jungquist C, Porock D. Person-centered dementia care and sleep in assisted living residents with dementia: a pilot study. Behav Sleep Med. 2017;15(2):97-113 https://doi.org/10.1080/15402 002.2015.1104686.

67. McGilton KS, Rochon E, Sidani S, Shaw A, Ben-David BM, Saragosa M, et al. Can we help care providers communicate more effectively with persons having dementia living in long-term care homes? Am J Alzheimers Dis Other Dement. 2017;32(1):41-50 https://doi.org/10.1177/1 533317516680899 .

68. Richter C, Berg A, Langner H, Meyer G, Köpke S, Balzer K, et al. Effect of person-centred care on antipsychotic drug use in nursing homes (EPCentCare): a cluster-randomised controlled trial. Age Ageing. 2019;48(3): 419-25 https://doi.org/10.1093/ageing/afz016.

69. Roberts G, Morley C, Walters W, Malta S, Doyle C. Caring for people with dementia in residential aged care: successes with a composite personcentered care model featuring Montessori-based activities. Geriatr Nurs. 2015;36(2):106-10 https://doi.org/10.1016/j.gerinurse.2014.11.003.

70. Sloane PD, Zimmerman S, Chen X, Barrick AL, Poole P, Reed D, et al. Effect of a person-centered mouth care intervention on care processes and outcomes in three nursing homes. J Am Geriatr Soc. 2013;61(7):1158-63 https://doi.org/10.1111/jgs.12317.

71. Sloane PD, Hoeffer B, Mitchell CM, McKenzie DA, Barrick AL, Rader J, et al. Effect of person-centered showering and the towel bath on bathingassociated aggression, agitation, and discomfort in nursing home residents with dementia: a randomized, controlled trial. J Am Geriatr Soc. 2004;52(11): 1795-804 https://doi.org/10.1111/j.1532-5415.2004.52501.x.

72. Sposito G, Barbosa A, Figueiredo D, Yassuda MS, Marques A. Effects of multisensory and motor stimulation on the behavior of people with dementia. Dementia. 2017;16(3):344-59 https://doi.org/10.1177/147130121 5592080 .
73. Wauters M, Elseviers M, Peeters L, Meester DD, Christiaens T, Petrovic M. Reducing Psychotripic drug use in nursing homes in Belgium: an implementation study for the roll-out of a practice improvement initiative. Drugs Aging. 2019;36(8):769-80. https://doi.org/10.1007/s40266-019-00686-5.

74. Williams KN, Perkhounkova Y, Jao YL, Bossen A, Hein M, Chung S, et al. Person-centered communication for nursing home residents with dementia: four communication analysis methods. West J Nurs Res. 2018;40(7):1012-31 https://doi.org/10.1177/0193945917697226.

75. Yasuda M, Sakakibara H. Care staff training based on person-centered care and dementia care mapping, and its effects on the quality of life of nursing home residents with dementia. Aging Ment Health. 2017;21(9):991-6 https://doi.org/10.1080/13607863.2016.1191056.

76. Cheng A, Morse K, Rudolph J, Arab AA, Runnacles J, Eppich W. Learnercentered debriefing for health care simulation education: lessons for faculty development. Simul Healthc. 2016;11(1):32-40 https://doi.org/10.1097/SIH. 0000000000000136

77. Ekström K, Spelmans S, Ahlström G, Nilsen P, Alftberg A, Wallerstedt B, et al. Next of kin's perceptions of the meaning of participation in the care of older persons in nursing homes: a phenomenographic study. Scand J Caring Sci. 2019;33(2):400-8 https://doi.org/10.1111/scs.12636.

78. Zhao FF, Suhonen R, Koskinen S, Leino-Kilpi H. Theory-based selfmanagement educational interventions on patients with type 2 diabetes: a systematic review and meta-analysis of randomized controlled trials. J Adv Nurs. 2017;73(4):812-33 https://doi.org/10.1111/jan.13163.

79. Santos J, Figueiredo AS, Vieira M. Innovative pedagogical practices in higher education: an integrative literature review. Nurse Educ Today. 2019;72:12-7 https://doi.org/10.1016/j.nedt.2018.10.003.

80. Lall P, Rees R, Yi Law GC, Dunleavy G, Cotič Ž, Car J. Influences on the implementation of mobile learning for medical and nursing education: qualitative systematic review by the digital health education collaboration. J Med Internet Res. 2019;21(2):e12895 https://doi.org/10.2196/12895.

81. O'Connor S, Jolliffe S, Stanmore E, Renwick L, Booth R. Social media in nursing and midwifery education: a mixed study systematic review. J Adv Nurs. 2018;74(10):2273-89 https://doi.org/10.1111/jan.13799.

82. Gorhan R, Carter L, Nowrouzi B, McLean N, Guimond M. Social media and health education: what the literature says. J Dist Educ. 2012;26(2):1-11.

83. Kitching F, Winbolt M, MacPhail A, Ibrahim JE. Web-based social media for professional medical education: perspectives of senior stakeholders in the nursing home sector. Nurse Educ Today. 2015;35(12):1192-8 https://doi. org/10.1016/..nedt.2015.05.013.

84. Ersek M, Polissar N, Du Pen A, Jablonski A, Herr K, Neradilek MB. Addressing methodological challenges in implementing the nursing home pain management algorithm randomized controlled trial. Clin Trials. 2012;9(5): 634-44 https://doi.org/10.1177/1740774512454243.

85. Maas ML, Kelley LS, Park M, Specht JP. Issues in conducting research in nursing homes. West J Nurs Res. 2002;24(4):373-89 https://doi.org/10.1177/ 01945902024004006

86. Crowther M, Lim W, Crowther MA. Systematic review and meta-analysis methodology. Blood. 2010;116(17):3140-6 https://doi.org/10.1182/blood-201 0-05-280883.

87. Olaussen A, Semple W, Oteir A, Todd P, Williams B. Paramedic literature search filters: optimised for clinicians and academics. BMC Med Inform Decis Mak. 2017;17(1):1-6 https://doi.org/10.1186/s12911-017-0544-z.

\section{Publisher's Note}

Springer Nature remains neutral with regard to jurisdictional claims in published maps and institutional affiliations.

\section{Ready to submit your research? Choose BMC and benefit from:}

- fast, convenient online submission

- thorough peer review by experienced researchers in your field

- rapid publication on acceptance

- support for research data, including large and complex data types

- gold Open Access which fosters wider collaboration and increased citations

- maximum visibility for your research: over $100 \mathrm{M}$ website views per year

At BMC, research is always in progress.

Learn more biomedcentral.com/submissions 